\title{
Efectos del ejercicio físico sobre marcadores antropométricos, fuerza muscular y presión arterial en pacientes con hemodiálisis: una revisión narrativa
}

\author{
Effects of physical exercise on anthropometric markers, muscle strength and \\ blood pressure in hemodialysis patients: A narrative review \\ Efeitos do exercício físico sobre marcadores antropométricos, força muscular e pressão \\ arterial em pacientes em hemodiálise: uma revisão narrativa
}

\author{
Ana Karen Pérez-Jiménez'1, Graciela Berenice Chávez-Becerril² Claudia Nelly Orozco-González³, \\ Saby Camacho-López ${ }^{4}$.
}

Recibido: 9 de mayo de 2021. Aceptado para publicación: 19 de octubre de 2021

Primero en línea: 22 de octubre de 2021

https://doi.org/10.35454/rncm.v4n4.297

\begin{abstract}
Resumen
Introducción: la implementación de programas de ejercicio puede mejorar la calidad de vida de pacientes en hemodiálisis (HD). Diversos estudios hablan sobre los beneficios del ejercicio físico en estos pacientes; sin embargo, los efectos sobre marcadores antropométricos, fuerza muscular y presión arterial (PA) según el tipo de ejercicio no han sido completamente evaluados. El objetivo de esta revisión es analizar estudios cuya intervención consistiera en la implementación de programas de ejercicio en pacientes con HD y proporcionar evidencias de sus efectos sobre los marcadores antropométricos, fuerza muscular y PA.
\end{abstract}

Métodos: se realizó una búsqueda en la literatura en Medline, LILACS, Scielo y Redalyc, con una temporalidad de 2015 a 2020. Se incluyeron 18 artículos en la presente revisión.

Resultados: la combinación de ejercicio anaeróbico y de resistencia aumenta la fuerza muscular y, de igual manera, el ejercicio aeróbico y anaeróbico incrementa la fuerza muscular de las extremidades superiores e inferiores de pacientes en HD. Por su parte, el ejercicio anaeróbico

\section{Summary}

Introduction: The implementation of exercise programs can improve quality of life in hemodialysis (HD) patients. Several studies discuss the benefits of physical exercise in these patients; however, the effects on anthropometric markers, muscle strength and blood pressure (BP), based on the type of exercise, have not been fully evaluated. The aim of the study is to analyze studies where the intervention consisted of the implementation of exercise programs in HD patients, and to provide evidence of their effects on anthropometric markers, muscle strength and BP.

Methods: A literature research was conducted in Medline, LILACS, Scielo and Redalyc covering a time period between 2015 and 2020. In total, 18 articles were included in this review.

Results: The combination of anaerobic and endurance exercise increases muscle strength; likewise, aerobic and anaerobic exercise increases muscle strength of the upper and lower extremities in HP patients. On the other hand, anaerobic exercise alone has effects on anthropometric markers, specifically on the increase in

\section{Resumo}

Introdução: A implementação de programas de exercício pode melhorar a qualidade de vida dos pacientes em hemodiálise (HD). Vários estudos falam sobre os benefícios do exercício físico nesses pacientes, no entanto, os efeitos sobre os marcadores antropométricos, força muscular e pressão arterial (PA) de acordo com o tipo de exercício não tem sido totalmente avaliados. O objetivo desta revisão é analisar estudos cuja intervenção consistiu na implementação de programas de exercício em pacientes com HD e fornecer evidências de seus efeitos sobre os marcadores antropométricos de força muscular e PA.

Métodos: Foi realizada uma pesquisa bibliográfica nas bases de dados de Medline, LILACS, Scielo e Redalyc, no período de 2015 a 2020. Foram incluídos 18 artigos na presente revisão.

Resultados: A combinação de exercício anaeróbio e resistido aumenta a força muscular e, da mesma forma, o exercício aeróbio e anaeróbio aumenta a força muscular das extremidades superiores e inferiores de pacientes em HD. Por outro lado, o exercício anaeróbio sozinho tem 
por sí solo tiene efectos sobre los marcadores antropométricos, específicamente en el aumento de masa libre de grasa. El ejercicio aeróbico aislado es eficaz para la disminución de la PA.

Conclusión: la implementación de programas de ejercicio en pacientes con HD ha demostrado tener efectos positivos sobre la fuerza muscular, los marcadores antropométricos y la PA.

Palabras clave: enfermedad renal crónica, hemodiálisis, ejercicio físico, marcadores antropométricos, fuerza muscular, presión arterial.

Escuela de Salud Pública de México. Cuernavaca, México.

Universidad de Ixtlahuaca (CUI). Ixtlahuaca, México.

3 Universidad Internacional Iberoamericana. Ciudad de México, México.

\section{INTRODUCCIÓN}

La enfermedad renal crónica (ERC) se define como la presencia de alteraciones en la estructura o función renal sostenida por al menos 3 meses, o bien por la disminución de la tasa de filtrado glomerular (TFG) por debajo de $60 \mathrm{~mL} / \mathrm{min} / 1,73 \mathrm{~m}^{2}$ con o sin daño renal ${ }^{(1)}$. La ERC es considerada como un grave problema de salud pública a nivel mundial debido a su elevada prevalencia e incidencia, así como a las complicaciones que conlleva $^{(2)}$. En 2017 se reportó una prevalencia de ERC del $12,2 \%$ y 51,4 muertes por cada 100000 habitantes en México ${ }^{(3)}$.

En la etapa terminal de la ERC es necesario un tratamiento sustitutivo como la hemodiálisis (HD), que es la terapia de reemplazo renal de mayor prevalencia en Latinoamérica $(82 \%)^{(4)}$. Por una parte, los pacientes sometidos a HD generalmente lo hacen 3 veces por semana, aproximadamente 4 horas por sesión, lo cual se considera un lapso de inactividad física que, a su vez, favorece una disminución de la capacidad funcional y debilidad muscular ${ }^{(5)}$. Por otra parte, la inactividad física en pacientes sometidos a $\mathrm{HD}$ es un factor de riesgo para desarrollar enfermedad cardiovascular (ECV), la cual es un concomitante común de la ERC y la principal causa de morbilidad y mortalidad de estos pacientes $^{(6)}$.

Existe una diferencia entre actividad física y ejercicio: el segundo es una variedad de la actividad física; efeitos nos marcadores antropométricos, especificamente no aumento da massa livre de gordura. $O$ exercício aeróbio isolado é eficaz na redução da PA.

Conclusão: A implementação de programas de exercício em pacientes em HD demonstrou efeitos positivos na força muscular, os marcadores antropométricos e a PA.

Palavras-chave: Doença renal crônica, hemodiálise, exercício físico, marcadores antropométricos, força muscular, pressão arterial.
4 Nutrir México. Ciudad de México, México

*Correspondencia: FALTA

FALTA CORREO sin embargo, es planificado, estructurado, repetitivo y realizado con un objetivo relacionado con la mejora de la aptitud física; mientras que la actividad física es cualquier movimiento corporal producido por los músculos esqueléticos que requiera de un gasto de energía ${ }^{(7)}$. El ejercicio se clasifica principalmente en aeróbico y anaeróbico, la diferencia entre ambos es el tiempo y la intensidad. En el primero, el movimiento es continuo y el organismo tiene mayor consumo de oxígeno, con este tipo de ejercicio se mejora la condición física, la respiración y oxigenación (por ejemplo: ciclismo, natación, caminatas, carreras). En el segundo, el movimiento es pausado y se requiere de mayor esfuerzo, ayuda a aumentar la fuerza, flexibilidad, elasticidad y resistencia (por ejemplo: levantar pesas u otro tipo de actividad para la tonificación de los músculos) ${ }^{(8)}$. Existen programas que combinan el ejercicio aeróbico y anaeróbico que favorecen la capacidad física y la calidad de vida de pacientes con ERC en estadios avanzados ${ }^{(9)}$. El entrenamiento físico intradialítico tiene un efecto positivo sobre la rigidez arterial, la composición corporal y el rendimiento físico de pacientes hemodializados cróni$\cos ^{(10)}$. El ejercicio ha demostrado tener un efecto positivo en la reducción de la presión arterial $(\mathrm{PA})^{(2)}$.

El objetivo de esta investigación fue analizar estudios cuya intervención consistía en la implementación de programas de ejercicio físico en pacientes con tratamiento de HD y proporcionar evidencias de sus efectos sobre marcadores antropométricos, fuerza muscular y PA. 


\section{MÉTODOS}

Se realizó una búsqueda de la literatura en Medline, LILACS, Scielo y Redalyc, para identificar publicaciones en las que se realizaron intervenciones con ejercicio físico en pacientes con ERC en HD.

Como criterios de inclusión se consideraron los siguientes: estudios experimentales (ensayos clínicos aleatorizados) y cuasiexperimentales (con grupo control no equivalente, de antes y después en un solo grupo, de medidas repetidas y de series temporales), en inglés y español, con una temporalidad de 2015 a 2020, esto con el objetivo de proporcionar información actualizada. Además, se incluyeron estudios que evaluaran los efectos del ejercicio físico sobre marcadores antropométricos, fuerza muscular o PA en pacientes con tratamiento de HD. Se consideraron solamente aquellos estudios que fueran realizados en humanos. Se excluyeron los metaanálisis y revisiones sistemáticas relacionadas con el tema de estudio, así como los protocolos.

Todos los artículos presentados son desde el punto de vista cuantitativo. La extracción de datos fue realizada por dos revisoras a través del análisis de datos secundarios en las bases de datos Medline, LILACS, Redalyc y Scielo. Las variables a medir fueron: marcadores antropométricos, fuerza muscular y PA. La evaluación de la elegibilidad fue efectuada por las mismas dos revisoras de manera independiente, no cegada y estandarizada.

\section{RESULTADOS}

Se incluyó un total de 18 artículos. La muestra inicial en todos los artículos fue de 660 pacientes. En el $39 \%$ de los artículos se realizaron intervenciones en las que se medía el efecto de los programas de ejercicio físico sobre la fuerza muscular, mientras que el $28 \%$ medía el efecto sobre los marcadores antropométricos y el $6 \%$ sobre la PA. Así mismo, el $22 \%$ analizaba los efectos sobre todas las variables mencionadas anteriormente y solo el $5 \%$ medía el efecto sobre los marcadores antropométricos y la PA.

\section{EFECTOS SOBRE LOS MARCADORES ANTROPOMÉTRICOS}

Chan y colaboradores ${ }^{(11)}$ efectuaron una intervención de ejercicio intradialítico anaeróbico y de resistencia progresiva, durante 12 semanas. En las primeras 4 semanas se realizaron 3 series de 12-15 repeticiones de cada ejercicio con una calificación de esfuerzo percibido (RPE) de 12-14 y en las últimas 8 semanas se realizaron
3 series de 10-12 repeticiones con una RPE de 14-15. Sin embargo, no se observaron cambios significativos en el peso corporal, índice de masa corporal (IMC) y circunferencia de cintura. En un estudio realizado por da Costa y colaboradores ${ }^{(12)}$ se llevó a cabo un entrenamiento anaeróbico y de resistencia progresiva durante 12 semanas, antes y durante la sesión de HD. Los pacientes fueron divididos aleatoriamente en un grupo experimental (E) y un grupo control (C). Se realizaron 11 ejercicios en 2 series de 15-20 repeticiones. El grupo $\mathrm{C}$ realizó ejercicios de muy baja intensidad sin carga y progresión. Se observó un aumento significativo de la masa magra localizada en las piernas del grupo E (de 14,36 [desviación estándar -DE-: 2,95] a 14,78 kg [DE: $3,27] ; p=0,04)$. No se observaron cambios significativos en la masa magra y masa grasa totales, así como en el IMC. Groussard y colaboradores ${ }^{(13)}$ llevaron a cabo un programa de ciclismo intradialítico (ejercicio aeróbico) durante 3 meses en el que los pacientes fueron asignados aleatoriamente a un grupo $\mathrm{E}$ o un grupo $\mathrm{C}$. Los sujetos pedalearon durante 15 minutos, la duración se incrementó gradualmente en 5 minutos durante la primera semana y luego en 10 minutos durante la segunda semana para llegar a 30 minutos después de 2 semanas. Sin embargo, el entrenamiento no modificó la composición corporal del grupo $\mathrm{E}$.

Marinho y colaboradores ${ }^{(14)}$ efectuaron un programa de entrenamiento anaeróbico intradialítico con ejercicios de resistencia durante 2 meses. Los ejercicios se realizaron en ambas extremidades inferiores y la intensidad media fue del $60 \%$ basada en la prueba de 3 repeticiones máximas (3RM). Sin embargo, no se observaron cambios significativos en la masa magra, IMC y grasa corporal después de la intervención.

Moraes y colaboradores ${ }^{(15)}$ realizaron un programa de ejercicio intradialítico (anaeróbico y de resistencia), durante 6 meses, en el que los pacientes fueron divididos en 2 grupos de estudio: grupo E y grupo C. Los ejercicios se realizaron en ambas extremidades inferiores y la intensidad se basó en la prueba de 1 repetición máxima (1RM). La intensidad inicial fue del $60 \%$ y alcanzó el $70 \%$ después de 12 sesiones. Se observó un aumento de masa libre de grasa (de 45,1 [DE: 11,1] a $46,7 \mathrm{~kg}$ [DE: 10,7]) del grupo E, así como una disminución de masa grasa (de 29,7 [DE: 6,7] a 28,9 \% [DE: $5,8]$ ); mientras que el grupo $C$ presentó ganancia de masa grasa (de 33,1 [DE: 7,9] a 34,5\% [DE: 7,6]) y disminuyó masa libre de grasa (de 45,4 [DE: 9,2] a 44,5 $\operatorname{kg}[\mathrm{DE}: 8,9])$. Bennett y colaboradores ${ }^{(16)}$ realizaron un programa de entrenamiento intradialítico de resistencia 
progresiva (ejercicio anaeróbico). Los pacientes fueron asignados aleatoriamente en 3 grupos de acuerdo con la duración del programa: grupo 1: 36 semanas, grupo 2: 24 semanas y grupo 3: 12 semanas. El programa consistía en 6 ejercicios de resistencia de la parte inferior y superior del cuerpo utilizando bandas elásticas ( 2 series de 15-20 repeticiones). Se observó una disminución significativa en el peso medio de los pacientes (de $76,11$ [DE: 18,42$]$ a $75,40 \mathrm{~kg}$ [DE: 1,38]).

Liao y colaboradores ${ }^{(17)}$ llevaron a cabo un programa intradialítico de ciclismo (ejercicio aeróbico) durante 3 meses y los pacientes fueron asignados aleatoriamente a 2 grupos, grupo $\mathrm{E}$ y un grupo $\mathrm{C}$. El programa de ejercicio consistió en un calentamiento de 5 minutos, 20 minutos de ciclismo y enfriamiento de 5 minutos, la intensidad del ejercicio fue de 12-15 en la escala de esfuerzo percibido de Borg. Sin embargo, no se observaron cambios significativos en el peso e IMC. Rhee y colaboradores ${ }^{(18)}$ realizaron un programa de entrenamiento intradialítico con una combinación de ejercicio aeróbico y anaeróbico durante 6 meses. Para el ejercicio aeróbico se utilizó una bicicleta ergonómica (adaptada a la cama) durante un mínimo de 30 minutos. Para el ejercicio anaeróbico se utilizaron bandas elásticas (extensión y flexión del codo, así como abducción lateral del hombro), 2-3 series, 10-15 repeticiones, durante 5-10 minutos. Sin embargo, no se observaron diferencias significativas en la circunferencia del brazo y del muslo. Cigarroa y colaboradores ${ }^{(19)}$ llevaron a cabo un programa de ejercicio intradialítico (fuerza-resistencia), durante 8 semanas, que consistía en 3 fases: calentamiento, ejercicios y vuelta a la calma. La intervención no generó cambios significativos en el peso e IMC.

Alonso y colaboradores ${ }^{(20)}$ implementaron un plan de ejercicio intradialítico (aeróbico y de resistencia), durante 16 semanas. En el ejercicio aeróbico se utilizó una pedalera, con un tiempo inicial de 15 minutos hasta llegar a 40 minutos. Mientras que en el ejercicio de resistencia se utilizaba una resistencia elástica para cuádriceps, dorsiflexores del pie y glúteos, comenzando con 3 series de 6-8 repeticiones hasta llegar a 5 series de 10-12 repeticiones. Se observó un aumento significativo de la masa magra (de 31,9 [DE: 9,0] a 32,7 kg [DE: $10,0] ; p=0,01$ ), pero no hubo cambios significativos en el peso seco ni en la masa grasa.

\section{EFECTOS SOBRE LA FUERZA MUSCULAR}

Alonso y colaboradores ${ }^{(20)}$ observaron que con una intervención de ejercicio intradialítico aeróbico y de resistencia no hubo cambios significativos en la fuerza muscular del cuádriceps y la empuñadura.

Una intervención realizada por Anding y colaboradores $^{(21)}$ con ejercicio de fuerza (ejercicio anaeróbico) y resistencia, con 1 año de duración, en la que los pacientes se dividieron en tres grupos de acuerdo con su nivel de adherencia en el programa (alta adherencia [HA], adherencia moderada $[\mathrm{MA}]$ y baja adherencia $[\mathrm{LA}])$, logró un aumento significativo de la fuerza muscular en las repeticiones de las pruebas de fuerza máxima para el grupo de HA en todos los grupos musculares $(p=0,00)$; mientras que para el grupo MA solo se observó una mejoría significativa en extensores de piernas $(p=0,00)$, abductor $(p=$ $0,00)$, abdomen $(p=0,03)$ y aductor $(p=0,04)$.

André de Castro y colaboradores ${ }^{(22)}$ demostraron que la implementación de un plan de ejercicio anaeróbico intradialítico, durante 39 meses, con ejercicios para dorsales, pectorales, deltoides, cuádriceps, isquiotibiales, pantorrilla, tríceps y bíceps aumenta significativamente la fuerza muscular (de 27,3 [DE: 11,58] a $34,8 \mathrm{~kg}$ [DE: 10,77$] ; p=0,00)$. Chan y colaboradores $^{(23)}$ evidenciaron que una intervención intradialítica con ejercicio anaeróbico y de resistencia progresiva durante 12 semanas en la que se considere el esfuerzo percibido por los pacientes y utilice una máquina portátil para la realización de ejercicios de la parte superior e inferior del cuerpo con cargas más pesadas, mientras se ejercitan con pesas de peso libre o bandas elásticas de resistencia los grupos musculares no aislados por el dispositivo de ejercicio, se logra un aumento significativo de la fuerza de agarre en las extremidades inferiores del cuerpo (de 62 [DE: 18,0] a $77 \mathrm{~kg}$ [DE: 21,0]; $p<$ 0,0001 ); sin embargo, no se encontraron cambios significativos en la fuerza de agarre de la extremidad donde era colocada la fístula. Dziubek y colaboradores ${ }^{(24)}$ realizaron una intervención con ejercicios acuáticos (ejercicio aeróbico y de resistencia) durante 3 meses, la cual consistía en calentamiento, ejercicios de resistencia $\mathrm{y}$ fortalecimiento de grupos musculares particulares, ejercicios de coordinación y, finalmente, ejercicios de relajación. Se observó un aumento significativo de la fuerza muscular (Newtons-metro [N-m]) en los músculos extensores de rodilla de la pierna derecha medidos en un ángulo articular de $60 \%$ s (de 62,31 [DE: $16,55]$ a $68,84 \mathrm{~N}-\mathrm{m}$ [DE: 15,25$] ; p=0,00) ; 180^{\circ} / \mathrm{s}$ (de $44,44$ [DE: 10,66] a 49,13 N-m [DE: 9,13]; $p=0,00)$ y $300^{\circ}$ s (de 38,39 [DE: 3,57 ] a 39,94 N-m [DE: 3,62]; $p=0,00)$,y en la pierna izquierda en un ángulo articular de $300^{\circ} / \mathrm{s}(36,63$ [DE: 5,03] a 39,24 N-m [DE: 6,31]; $p=0,04)$. Asimismo, se observó un aumento significa- 
tivo en los músculos flexores de la rodilla de la pierna derecha medidos en un ángulo articular de $60 \%$ s (de $34,80$ [DE: 7,80] a 40,36 N-m [DE: 6,74]; $p=0,01)$ y $180^{\circ}$ s (de 26,20 [DE: 4,91] a 31,38 N-m [DE: 7,36] $p=0,02$ ). Además, en la pierna izquierda en un ángulo articular de $180^{\circ}$ s (de 24,83 [DE: 5,91] a 30,41 N-m [DE: 7,89$] ; p=0,02)$ y $300^{\circ} / \mathrm{s}$ (de 25,96 [DE: 3,93$]$ a 2,24 N-m [DE: 4,04]; $p=0,00$ ).

Junqué y colaboradores ${ }^{(25)}$ implementaron una intervención con ejercicio aeróbico y anaeróbico durante 12 semanas que constaba de calentamiento, trabajo de capacidad anaeróbica, fuerza, coordinación y flexibilidad de diferentes grupos musculares, así como de capacidad aeróbica utilizando cicloergómetros eléctricos. Como resultado se obtuvo un aumento significativo $(p=0,02)$ en la fuerza de empuñadura del brazo dominante (de 16,6 [DE: 8,7] a 18,2 kg [DE: $8,9]$ ). Simó y colaboradores ${ }^{(26)}$ implementaron un programa de ejercicio intradialítico (aeróbico y anaeróbico) durante 12 semanas en el que los pacientes fueron asignados a dos grupos, grupo $\mathrm{E}$ y grupo $\mathrm{C}$, el cual consistía en calentamiento, capacidad anaeróbica (coordinación y flexibilidad en diferentes grupos musculares) y capacidad aeróbica (utilizando cicloergómetros eléctricos). Se observó un aumento significativo $(p=0,01)$ de la fuerza muscular de empuñadura para el grupo E (de 16,6 [DE: 8,7] a 18,2 kg [DE: 8,9]) y una disminución significativa $(p=0,01)$ en el grupo $\mathrm{C}$ (de 19,9 [DE: 9,4] a 18,3 kg [DE: 10,6]). En cuanto a la fuerza muscular de las extremidades inferiores, se observó una mejoría en el grupo E; sin embargo, no fue significativa.

Chang y colaboradores ${ }^{(27)}$ implementaron un programa de ejercicio físico con taichí de estilo corto, de 13 movimientos (ejercicio aeróbico), durante 12 semanas, en el que los pacientes fueron asignados de acuerdo con sus preferencias al grupo $\mathrm{E}$ o al grupo C. Como resultado, se observó un aumento significativo $(p=0,00)$ de la resistencia muscular en el grupo E. La intervención con ejercicios de fuerza-resistencia muscular realizada por Cigarroa y colaboradores ${ }^{(22)}$ dio como resultado un aumento significativo de la fuerza muscular en el miembro inferior derecho (de 223,8 $\pm 20,3$ a $232,9 \pm 18,8$ puntos; $p=0,02$ ) y en el miembro inferior izquierdo (de 222,3 $\pm 18,9$ a 232,0 $\pm 18,0$ puntos; $p=0,00$ ).

En el estudio de Bennetty colaboradores ${ }^{(16)}$ se observó que, con un programa de entrenamiento de resistencia progresiva (anaeróbico) intradialítico, la fuerza muscular media cambia significativamente (de 9,79 [DE: 5,11] a $9,71$ repeticiones [DE: 0,42$]$; $p<0,001)$. Por su parte,
Rhee y colaboradores ${ }^{(18)}$ demostró que un programa de ejercicio intradialítico con una combinación de ejercicio aeróbico y anaeróbico puede mejorar significativamente la potencia muscular de la espalda (de 44,5 [DE: 22,1] a $56,9 \mathrm{~kg}$ [DE: 25,7]; $p=0,00)$.

\section{EFECTOS SOBRE LA PA}

Musavian y colaboradores ${ }^{(28)}$ llevaron a cabo un programa intradialítico de ejercicios aeróbicos pasivos y activos de pedaleo, con una duración de 8 meses. Durante las primeras 8 semanas del programa los pacientes hicieron ejercicio pasivo utilizando una minibicicleta con motor eléctrico adaptada a su cama y las siguientes 8 semanas hicieron ejercicio activo de manera similar, excepto que la minibicicleta no se conectó a la energía eléctrica y pedalearon activamente. Se observó que la PA diastólica media (kilopascales $[\mathrm{kPa}])$ disminuyó significativamente $(p=0,03)$ al final de la cuarta y octava semanas del ejercicio pasivo (inicio: $8,06 \mathrm{kPa}$ [DE: 0,77]; final de la 4. ${ }^{\text {a }}$ semana: 7,56 $\mathrm{kPa}$ [DE: 0,62]; final de la 8. a semana: 7,69 kPa [DE: $0,70])$. En el estudio realizado por Bennett y colaboradores $^{(16)}$ se implementó un programa de entrenamiento de resistencia progresiva (anaeróbico) intradialítico y mostró cambios significativos en el valor medio de PA (de 94,45 [DE: 13,94] a 94,28 mm Hg [DE: 0,99]; $p$ $<0,01)$. Por su parte, Liao y colaboradores ${ }^{(17)}$ revelaron que un programa de ciclismo intradialítico (ejercicio aeróbico) puede modificar las cifras de PA de la siguiente manera: PA sistólica antes del ejercicio: de 138,1 (DE: 16,9) a 96,0 mm Hg (DE: 64,2); durante el ejercicio: de 149,4 (DE: 17,3) a 104,2 mm Hg (DE: 69,2) y después del ejercicio: de 136,8 (DE: 13,8) a $96,6 \mathrm{~mm} \mathrm{Hg}$ (DE: 64,1); y la PA diastólica antes del ejercicio: de 76,8 (DE: 8,3 ) a 53,7 mm Hg (DE: 35,3); durante el ejercicio: de 79,3 (DE: 8,4) a 55,8 $\mathrm{mm} \mathrm{Hg}$ (DE: 36,7) y después del ejercicio: de 74,1 (DE: 6,8) a $53,1 \mathrm{~mm} \mathrm{Hg}$ (DE: 34,9).

Cigarroa y colaboradores ${ }^{(19)}$ encontraron que con una intervención de ejercicio anaeróbico y de resistencia muscular se puede obtener una disminución significativa en la PA diastólica (de 93,9 $\pm 3,6$ a 88,6 $\pm 2,8$; $p$ $=0,04$ ), pero no en la PA sistólica; mientras que Alonso y colaboradores ${ }^{(25)}$ encontraron cambios significativos en la PA diastólica predialítica (de 114,0 [DE: 18,0] a 109,0 mm Hg [DE: 13,0]; $p=0,02$ ), PA sistólica posdialítica (de 85,0 [DE: 13,0] a 72,0 mm Hg [DE: 8,0]; $p<0,0001)$ y PA diastólica posdialítica (de 79,0 [DE: $11,0]$ a 62,0 [DE: 8,0]; $p<0,0001)$. 
Con respecto a los posibles riesgos y efectos adversos, solamente 3 de los 18 artículos incluidos refirieron la presencia de efectos adversos ${ }^{(18,23,28)}, 2$ mencionaban los riesgos potenciales de la intervención ${ }^{(21,24)}, 8$ reportaron que los pacientes no presentaron efectos adversos relacionados ${ }^{(14,16,17,19,22,24-26)}$ y 5 no reportaron la información $^{(12,13,15,20,27)}$.

En la Tabla 1 se muestra el resumen de los artículos incluidos en la presente revisión.

\section{DISCUSIÓN}

La malnutrición es una complicación frecuente y un factor de riesgo asociado con la mortalidad de los pacientes con $\mathrm{HD}^{(29)}$; sin embargo, se ha demostrado que los programas de ejercicio físico mejoran la composición corporal de estos pacientes ${ }^{(30,31)}$. La disminución de la ingesta, las alteraciones hormonales y metabólicas, el daño neurohepático y la aparición de toxinas urémicas provocan que los pacientes en $\mathrm{HD}$ caigan en un estado catabólico que conduce a la pérdida de masa y fuerza muscular, aunque cuenten con un peso adecuado ${ }^{(32-34)}$. La masa muscular es esencial para el desarrollo de fuerza muscular y su pérdida es considerada como el predictor más importante de mortalidad en pacientes hemodializados ${ }^{(34,35)}$.

La ECV es la primera causa de muerte en los pacientes con $\mathrm{HD}^{(2)}$ y el ejercicio físico regular puede mejorar el control de su hipertensión arterial (HTA) ${ }^{(36,37)}$.

La presente revisión resalta la importancia de implementar un programa de ejercicio físico en pacientes con $\mathrm{HD}$, ya que ha demostrado tener un efecto positivo en los marcadores antropométricos, la fuerza muscular y la $\mathrm{PA}^{(17-23,28,32-38)}$. Se incluyeron estudios experimentales y cuasiexperimentales, ya que, al estar enfocados al estudio de intervenciones o medidas terapéuticas, permitieron analizar las intervenciones con ejercicio físico implementadas en los pacientes con HD y sus efectos. Por una parte, los estudios experimentales son considerados como los de mayor peso metodológico y en esta revisión se incluyeron 5 de estos estudios ${ }^{(12-14,16,17)}$, lo que aumenta la confiabilidad de sus resultados. Por otra parte, aunque los estudios cuasiexperimentales tienen un menor grado de validez, también son muy útiles para evaluar una intervención y en esta revisión se incluyeron 13 estudios ${ }^{(11,15,17,18,20,21-28)}$. La población que se estudiaba en los artículos era variable e iba desde $13^{(17)}$ hasta $171^{(16)}$ sujetos incluidos y en todos se incluían tanto hombres como mujeres. Con la finalidad de disminuir la cantidad de abandonos, los pacientes fueron vigilados durante el período del estudio. Se encontró que las intervenciones que resultaban más efectivas eran aquellas que tenían una duración mínima de 30 minutos por sesión, durante 12 semanas; sin embargo, a mayor tiempo de exposición al programa de ejercicios, mayores eran los beneficios para los pacientes $^{(11,14,17,18,20-23,31,32,34-38)}$.

Por un lado, con respecto al aumento de fuerza muscular, se puede decir que, de acuerdo con diversos estu$\operatorname{dios}^{(11,14,17)}$, la combinación de ejercicio anaeróbico con ejercicio de resistencia muscular resulta altamente efectivo y, por tanto, recomendable. Por otro lado, en lo que a efectos observados sobre marcadores antropométricos se refiere, la realización de ejercicio anaeróbico parece ser la opción más recomendable para aumentar masa libre de $\operatorname{grasa}^{(12,34)}$; sin embargo, aunque sí hubo resultados positivos para la disminución de masa grasa, circunferencia de cintura, peso e IMC, estos no fueron significativos ${ }^{(33,35-37)}$. De igual manera, se identificó que el entrenamiento combinado de ejercicio aeróbico y anaeróbico intradialítico tiene efectos positivos sobre la fuerza muscular de la espalda, aunque no resulta ser tan eficiente en la circunferencia de brazo y muslo, así como en la $\mathrm{PA}^{(37)}$.

Se logró identificar que el entrenamiento acuático (aeróbico y de resistencia) incrementa la aptitud física, particularmente en la fuerza muscular de las extremidades superiores e inferiores ${ }^{(20)}$. Así mismo, se observó que el ciclismo intradialítico (ejercicio aeróbico) es eficaz para la disminución de la $\mathrm{PA}^{(26,36)}$, pero este tipo de ejercicio no resulta ser tan eficiente para la modificación de peso, IMC, grasa corporal y masa libre de grasa ${ }^{(32,36)}$. Además, por un lado, se observó que este tipo de ejercicio disminuye la PA una hora después en comparación con los niveles en reposo y, pese a las asociaciones desfavorables de la hipotensión intradialítica, no hay evidencia concreta que sugiera que el ejercicio cause alguna lesión al miocardio; y, por otro lado, se debe evitar el ejercicio al final de la sesión de HD para los pacientes susceptibles a la hipotensión, así como a los que se les extraigan grandes cantidades de líquido ${ }^{(39)}$.

Otro hallazgo de interés es que, aun en los pacientes ancianos sometidos a HD, el ejercicio físico aeróbico y anaeróbico intradialítico aumenta la fuerza muscular de la empuñadura del brazo dominante y de las extremidades inferiores ${ }^{(13,30)}$; por tanto, la implementación de programas de ejercicio intradialítico podría considerarse como parte del cuidado integral de estos pacientes. En ese sentido, la realización de ejercicio ayuda al mejoramiento del estado nutricional, la composición corporal y, por ende, a la calidad de vida de los pacientes ${ }^{(34)}$. 
Tabla 1. Principales características y resultados de los estudios incluidos

\begin{tabular}{|c|c|c|c|c|c|c|}
\hline Artículo & Intervención & Tipo de estudio & Población & Hallazgos o resultados & $\begin{array}{c}\text { Métodos de medición } \\
\text { de desenlaces }\end{array}$ & $\begin{array}{c}\text { Riesgos/efectos } \\
\text { adversos } \\
\text { observados }\end{array}$ \\
\hline $\begin{array}{l}\text { Anding, } \\
2015^{(21)}\end{array}$ & $\begin{array}{l}\text { Ejercicio anaeróbico y de resistencia } \\
\text { muscular, intradialítico (plan de ejercicio } \\
\text { para los } 8 \text { grupos musculares: extensor } \\
\text { de piernas, flexión de piernas, aductor, } \\
\text { abdomen, bíceps, tríceps y abductor, } \\
\text { y resistencia con un cicloergómetro), } 2 \\
\text { sesiones/semana, } 60 \text { minutos/sesión, } \\
\text { durante } 1 \text { año. Los pacientes se dividieron } \\
\text { de acuerdo con su nivel de adherencia en } 3 \\
\text { grupos de estudio (HA }>80 \% ; n=19 ; \text { MA }= \\
60 \%-80 \% ; n=12 ; \text { y LA }<60 \%, n=15 \text { ). }\end{array}$ & $\begin{array}{l}\text { Estudio cuasiex- } \\
\text { perimental de } \\
\text { medidas repe- } \\
\text { tidas }\end{array}$ & $\begin{array}{l}46 \text { pacientes en } \\
\text { tratamiento de } \mathrm{HD} \text {, } \\
24 \text { hombres y } 22 \\
\text { mujeres, con una } \\
\text { edad media de } 63,2 \\
\text { años (DE*: } 16,3 \text { ) }\end{array}$ & $\begin{array}{l}\text { Mejora estadísticamente significativa } \\
\text { para los grupos HA y MA en fuerza (HA: } \\
>120 \%, \text { MA: } 40 \%-50 \% ; p=0,00) \text {. } \\
\text { Aumento significativo de la fuerza } \\
\text { muscular en las repeticiones en las } \\
\text { pruebas de fuerza máxima hacia el final } \\
\text { del estudio después de } 12 \text { meses y solo } \\
\text { para algunos de los grupos musculares; } \\
\text { es decir, para el extensor de pierna ( } p= \\
0,00) \text {, aductor }(p=0,04) \text {, abdomen }(p= \\
0,03) \text { y abductor }(p=0,00)\end{array}$ & $\begin{array}{l}\text { Fuerza muscular: } \\
\text { Prueba sit-to-stand 60S } \\
\text { (STS60) o prueba de } \\
\text { sentarse y pararse de } \\
60 \text { segundos }\end{array}$ & $\begin{array}{l}\text { Posibles } \\
\text { riesgos de la } \\
\text { intervención: } \\
\text { fatiga muscular }\end{array}$ \\
\hline $\begin{array}{l}\text { Dziubek, } \\
2015^{(24)}\end{array}$ & $\begin{array}{l}\text { Ejercicio aeróbico y de resistencia en } \\
\text { días sin HD (entrenamientos acuáticos: } \\
\text { calentamiento, seguido de ejercicios de } \\
\text { resistencia, fortalecimiento muscular y } \\
\text { ejercicios de coordinación, finalmente } \\
\text { ejercicios de estiramiento, respiración y } \\
\text { relajación) } 1 \text { sesión/semana, } 60 \text { minutos } \\
\text { por sesión, durante } 3 \text { meses supervisado } \\
\text { por un fisioterapeuta, un médico y un } \\
\text { salvavidas }\end{array}$ & $\begin{array}{l}\text { Estudio cuasiex- } \\
\text { perimental de } \\
\text { antes y después } \\
\text { en un solo grupo }\end{array}$ & $\begin{array}{l}20 \text { pacientes en } \\
\text { tratamiento de } \mathrm{HD} \text {, } \\
4 \text { hombres y } 16 \\
\text { mujeres, con una } \\
\text { edad media de } 64,2 \\
\text { años (DE: } 13,1)\end{array}$ & 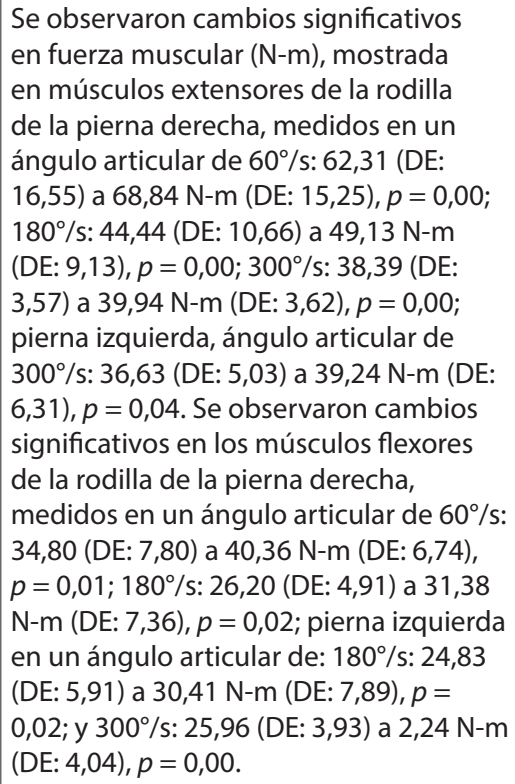 & $\begin{array}{l}\text { Fuerza muscular de } \\
\text { las extremidades } \\
\text { inferiores: } \\
\text { dinamómetro } \\
\text { isocinético Biodex } \\
\text { Multi-Joint System } 3\end{array}$ & $\begin{array}{l}\text { Posibles } \\
\text { riesgos de la } \\
\text { intervención: } \\
\text { cansancio, } \\
\text { náuseas, vómitos, } \\
\text { dificultad para } \\
\text { respirar, mareos, } \\
\text { dolor muscular, } \\
\text { articular o } \\
\text { coronario }\end{array}$ \\
\hline
\end{tabular}


Tabla 1. Principales características y resultados de los estudios incluidos (continuación)

\begin{tabular}{|c|c|c|c|c|c|c|}
\hline Artículo & Intervención & Tipo de estudio & Población & Hallazgos o resultados & $\begin{array}{c}\text { Métodos de medición } \\
\text { de desenlaces }\end{array}$ & $\begin{array}{l}\text { Riesgos/efectos } \\
\text { adversos } \\
\text { observados }\end{array}$ \\
\hline $\begin{array}{l}\text { Groussard, } \\
2015^{(13)}\end{array}$ & $\begin{array}{l}\text { Ejercicio aeróbico intradialítico (ciclismo } \\
\text { con el } 55 \%-60 \% \text { de la potencia máxima) } \\
3 \text { sesiones/semana, } 30 \text { minutos/sesión, } \\
\text { durante } 3 \text { meses. Los pacientes se } \\
\text { dividieron en } 2 \text { grupos de estudio, grupo } \\
\text { E }(n=8) \text { y grupo } C(n=10) \text {. El grupo } C \\
\text { no recibió el programa de ejercicio. Fue } \\
\text { supervisado por un equipo profesional } \\
\text { con experiencia en actividad física. }\end{array}$ & $\begin{array}{l}\text { Estudio experi- } \\
\text { mental aleato- } \\
\text { rizado no cegado }\end{array}$ & $\begin{array}{l}18 \text { pacientes en } \\
\text { tratamiento de } H D \text {, } \\
\text { grupo E: } 5 \text { hombres } \\
\text { y } 3 \text { mujeres con } \\
\text { una edad media de } \\
66,5 \text { años (DE: } 4,6), \\
\text { grupo C: } 7 \text { hombres } \\
\text { y } 2 \text { mujeres con una } \\
\text { edad media de } 68,4 \\
\text { años (DE: } 3,7)\end{array}$ & $\begin{array}{l}\text { No se observaron modificaciones } \\
\text { significativas en los marcadores } \\
\text { antropométricos del grupo E: peso }(\mathrm{kg}) \text { : } \\
78,1 \pm 6,4 \text { a } 78,3 \pm^{*} 6,0 ; \mathrm{IMC}\left(\mathrm{kg} / \mathrm{m}^{2}\right): \\
29,4 \pm 2,1 \text { a } 29,5 \pm 1,9 ; \text { grasa corporal } \\
(\%): 32,2 \pm 3,1 \text { a } 32,4 \pm 3,2 ; \text { masa libre de } \\
\text { grasa }(\mathrm{kg}): 51,8 \pm 4,7 \text { a } 52,2 \pm 4,9 ; \text { masa } \\
\text { libre de grasa en miembros inferiores } \\
\text { (kg): } 16,3 \pm 1,8 \text { a } 16,3 \pm 1,9\end{array}$ & $\begin{array}{l}\text { Composición corporal: } \\
\text { absorciometría de } \\
\text { rayos X de energía } \\
\text { dual (DEXA) }\end{array}$ & $\begin{array}{l}\text { Información no } \\
\text { reportada }\end{array}$ \\
\hline $\begin{array}{l}\text { Junqué, } \\
2015^{(25)}\end{array}$ & $\begin{array}{l}\text { Ejercicio aeróbico y anaeróbico } \\
\text { intradialítico (capacidad anaeróbica: } \\
\text { fuerza, coordinación y flexibilidad } \\
\text { muscular mediante cintas elásticas de } \\
\text { resistencia, balones medicinales, pelotas } \\
\text { de contracción, tobilleras con peso } \\
\text { añadido, mancuernas y pesas. Capacidad } \\
\text { aeróbica: ciclismo con una intensidad } \\
\text { de 40-50-60 rpm y una duración de } \\
\text { 3-6-9-12-15 min) } 2 \text { sesiones/semana, } \\
45-50 \text { minutos aproximadamente/sesión, } \\
\text { durante } 12 \text { semanas. Fue supervisado y } \\
\text { dirigido por el personal de enfermería del } \\
\text { hospital. }\end{array}$ & $\begin{array}{l}\text { Estudio cuasiex- } \\
\text { perimental de } \\
\text { antes y después } \\
\text { en un solo grupo }\end{array}$ & $\begin{array}{l}11 \text { pacientes en } \\
\text { tratamiento de } \\
\text { HD, } 4 \text { hombres y } 7 \\
\text { mujeres, con una } \\
\text { edad media de } 83,9 \\
\text { años (DE: } 3,9)\end{array}$ & $\begin{array}{l}\text { Se observó una mejoría significativa en } \\
\text { la fuerza muscular de la empuñadura del } \\
\text { brazo dominante (kg): } 16,6 \text { (DE: } 8,7) \text { a } \\
\text { 18,2 (DE: } 8,9) \text {; diferencia: } 1,6 ; p=0,02 \text {. }\end{array}$ & $\begin{array}{l}\text { Fuerza muscular de } \\
\text { las extremidades } \\
\text { superiores: } \\
\text { dinamómetro } \\
\text { homologado tipo } \\
\text { Jamar (Hand-grip } \\
\text { dynamometer) (HG) en } \\
\text { el brazo dominante. } \\
\text { Fuerza muscular de } \\
\text { las extremidades } \\
\text { inferiores: } \\
\text { dinamómetro de } \\
\text { tracción homologado } \\
\text { tipo Kern (Kern CH50 } \\
50 \text { KG dynamometer). }\end{array}$ & $\begin{array}{l}\text { No se observaron } \\
\text { efectos adversos } \\
\text { relacionados. }\end{array}$ \\
\hline $\begin{array}{l}\text { Moraes, } \\
2015^{(15)}\end{array}$ & $\begin{array}{l}\text { Ejercicio anaeróbico intradialítico (ejercicios } \\
\text { de resistencia en ambas extremidades } \\
\text { inferiores, } 60 \%-70 \% \text { de intensidad basada } \\
\text { en la prueba de } 1 \text { repetición máxima [1RM], } \\
\text { se utilizaron tobilleras y bandas elásticas, la } \\
\text { intensidad variaba dependiendo del color } \\
\text { de las bandas) } 3 \text { sesiones/semana, en las } \\
\text { primeras } 2 \text { horas de HD, durante } 6 \text { meses } \\
(72 \text { sesiones). Los pacientes se dividieron } \\
\text { en } 2 \text { grupos de estudio: grupo } \mathrm{E}(\mathrm{n}=37) \text { y } \\
\text { grupo } \mathrm{C}(\mathrm{n}=15) \text {. El grupo } \mathrm{C} \text { no recibió el } \\
\text { programa de ejercicio. Fue supervisado por } \\
\text { un educador físico. }\end{array}$ & $\begin{array}{l}\text { Estudio cuasiex- } \\
\text { perimental con } \\
\text { grupo control no } \\
\text { equivalente }\end{array}$ & $\begin{array}{l}52 \text { pacientes en } \\
\text { tratamiento de } \\
\text { HD. Grupo E: } \\
21 \text { hombres y } \\
16 \text { mujeres con } \\
\text { una edad media } \\
\text { de } 45 \text { años (DE: } \\
12,8) \text {, grupo C: } \\
10 \text { hombres y } 5 \\
\text { mujeres con una } \\
\text { edad media de } 50 \\
\text { años (DE: } 10,6)\end{array}$ & $\begin{array}{l}\text { Se observó un aumento de masa libre } \\
\text { de grasa (kg) del grupo E después de la } \\
\text { intervención: } 45,1 \text { (DE: 11,1) a 46,7 (DE: } \\
\text { 10,7) y disminución de masa grasa (\%): } \\
29,7 \text { (DE: } 6,7) \text { a } 28,9 \text { (DE: 5,8); mientras } \\
\text { que el grupo C presentó ganancia de } \\
\text { masa grasa (\%): } 33,1 \text { (DE: } 7,9 \text { ) a } 34,5 \text { (DE: } \\
\text { 7,6) y disminución de masa libre de grasa } \\
\text { (kg): } 45,4 \text { (DE: } 9,2 \text { ) a 44,5 (DE: 8,9). No se } \\
\text { observó mejoría en el IMC (kg/m²) del } \\
\text { grupo E: } 23,5(D E: 3,9) \text { a } 24,0(D E: 4,3) \text {. }\end{array}$ & $\begin{array}{l}\text { Composición corporal: } \\
\text { calibrador de pliegues } \\
\text { cutáneos Lange } \\
\text { (Cambridge Scientific } \\
\text { Products, Cambridge, } \\
\text { MA). }\end{array}$ & $\begin{array}{l}\text { Información no } \\
\text { reportada }\end{array}$ \\
\hline
\end{tabular}


Tabla 1. Principales características y resultados de los estudios incluidos (continuación)

\begin{tabular}{|c|c|c|c|c|c|c|}
\hline Artículo & Intervención & Tipo de estudio & Población & Hallazgos o resultados & $\begin{array}{c}\text { Métodos de medición } \\
\text { de desenlaces }\end{array}$ & $\begin{array}{c}\text { Riesgos/efectos } \\
\text { adversos } \\
\text { observados }\end{array}$ \\
\hline $\begin{array}{l}\text { Musavian, } \\
2015^{(28)}\end{array}$ & $\begin{array}{l}\text { Ejercicio aeróbico intradialítico } \\
\text { (ciclismo: ejercicios pasivos, pedaleo en } \\
\text { una minibicicleta con motor eléctrico, } \\
\text { realizando } 3 \text { series de ejercicios; ejercicios } \\
\text { activos, el pedaleo se realizó de manera } \\
\text { similar, excepto que la minibicicleta no } \\
\text { se conectó a la energía eléctrica y los } \\
\text { pacientes pedalearon activamente) } 3 \\
\text { sesiones/semana, } 30 \text { minutos/sesión } \\
\text { durante } 8 \text { meses. }\end{array}$ & $\begin{array}{l}\text { Estudio cuasiex- } \\
\text { perimental de } \\
\text { medidas repe- } \\
\text { tidas }\end{array}$ & $\begin{array}{l}16 \text { pacientes en } \\
\text { tratamiento de } \\
H D, 13 \text { hombres } \\
\text { y } 3 \text { mujeres, con } \\
\text { una edad media } \\
\text { de } 51,98 \text { años (DE: } \\
1,57 \text { ) }\end{array}$ & $\begin{array}{l}\text { La PA diastólica media ( } \mathrm{kPa} \text { ) del } \\
\text { ejercicio intradialíticopasivo disminuyó } \\
\text { significativamente al final de la cuarta y } \\
\text { octava semanas de intervención. Inicio: } \\
8,06 \mathrm{kPa}(\mathrm{DE}: 0,77) \text {, final } 4 .{ }^{\text {a }} \text { semana: } 7,56 \\
\mathrm{kPa}(\mathrm{DE}: 0,62), \text { final } 8{ }^{\text {a }} \text { semana: } 7,69 \mathrm{kPa} \\
\text { (DE: } 0,70) ; p=0,03 \text {. }\end{array}$ & $\begin{array}{l}\text { PA: } \\
\text { esfigmomanómetro } \\
\text { de mercurio }\end{array}$ & $\begin{array}{l}\text { Un caso de } \\
\text { efectos adversos } \\
\text { fue reportado: } \\
\text { el paciente } \\
\text { presentó } \\
\text { hipertensión. }\end{array}$ \\
\hline $\begin{array}{l}\text { Simó, } \\
2015^{(26)}\end{array}$ & $\begin{array}{l}\text { Ejercicio aeróbico y anaeróbico intradialítico } \\
\text { (anaeróbico: coordinación y flexibilidad } \\
\text { muscular mediante cintas elásticas de } \\
\text { resistencia, balones medicinales, pelotas de } \\
\text { contracción, tobilleras con peso añadido, } \\
\text { mancuernas y pesas; aeróbico: ciclismo } \\
\text { con una intensidad de } 40-50-60 \text { rpm y una } \\
\text { duración de } 3-6-9-12-15 \text { min) } 2 \text { sesiones/ } \\
\text { semana, } 45-50 \text { minutos aproximadamente/ } \\
\text { sesión durante } 12 \text { semanas. Los pacientes } \\
\text { se dividieron en } 2 \text { grupos de estudio, grupo } \\
\text { E ( } n=11 \text { ) y grupo } C \text { ( } n=11 \text { ). El grupo C } \\
\text { recibía el cuidado habitual en HD. Fue } \\
\text { supervisado y dirigido por el personal de } \\
\text { enfermería del hospital. }\end{array}$ & $\begin{array}{l}\text { Estudio cuasiex- } \\
\text { perimental con } \\
\text { grupo control no } \\
\text { equivalente }\end{array}$ & $\begin{array}{l}22 \text { pacientes en } \\
\text { tratamiento de } H D \text {, } \\
11 \text { hombres y } 11 \\
\text { mujeres, con una } \\
\text { edad media de } 83,2 \\
\text { años (DE: } 4,2 \text { ) }\end{array}$ & $\begin{array}{l}\text { Se observó una mejoría significativa en } \\
\text { la fuerza muscular de las extremidades } \\
\text { superiores en el grupo } \mathrm{E} \text {, después de } \\
\text { la intervención: } 16,6 \text { (DE: } 8,7 \text { ) a } 18,2 \mathrm{~kg} \\
\text { (DE: } 8,9), p=0,01 ; \text { así como un deterioro } \\
\text { significativo en el grupo C: } 19,9 \text { (DE: } 9,4) \\
\text { a } 18,3 \text { (DE: } 10,6), p=0,01 \text {. En cuanto a } \\
\text { la fuerza muscular de las extremidades } \\
\text { inferiores, se observó una mejoría en } \\
\text { el grupo } \mathrm{E}: 10,5 \text { (DE: } 7,6 \text { ) a 12,9 kg (DE: } \\
\text { 10,1), } p=0,06 \text {. }\end{array}$ & $\begin{array}{l}\text { Fuerza muscular de } \\
\text { las extremidades } \\
\text { superiores: } \\
\text { dinamómetro } \\
\text { homologado tipo } \\
\text { Jamar (Hand-grip } \\
\text { dynamometer) (HG) en } \\
\text { el brazo dominante. } \\
\text { Fuerza muscular } \\
\text { en extremidades } \\
\text { inferiores: } \\
\text { dinamómetro de } \\
\text { tracción homologado } \\
\text { tipo Kern (Kern CH50 } \\
50 \text { KG dynamometer). }\end{array}$ & $\begin{array}{l}\text { No se observaron } \\
\text { efectos adversos } \\
\text { relacionados. }\end{array}$ \\
\hline $\begin{array}{l}\text { Bennett, } \\
2016^{(16)}\end{array}$ & $\begin{array}{l}\text { Ejercicio anaeróbico intradialítico } \\
\text { (abducción de pierna, flexión plantar, } \\
\text { dorsiflexión, pierna recta y elevación de } \\
\text { rodilla flexionada, extensión y flexión de } \\
\text { rodilla) } 3 \text { sesiones/semana, } 1 \text { hora/sesión. } \\
\text { Los pacientes se dividieron en } 3 \text { grupos } \\
\text { de estudio: grupo } 1(\mathrm{G} 1 ; \mathrm{n}=51) \text { con un } \\
\text { período de intervención de } 12 \text { semanas, } \\
\text { grupo } 2(\mathrm{G} 2 ; \mathrm{n}=61) \text { con } 24 \text { semanas } \\
\text { de intervención y grupo } 3(\mathrm{G} 3 ; \mathrm{n}=59) \\
\text { con } 36 \text { semanas de intervención. Fue } \\
\text { supervisado por fisiólogos del ejercicio } \\
\text { acreditados. }\end{array}$ & $\begin{array}{l}\text { Estudio experi- } \\
\text { mental aleato- } \\
\text { rizado no cegado }\end{array}$ & $\begin{array}{l}171 \text { participantes } \\
\text { en tratamiento de } \\
\text { HD, } 107 \text { hombres y } \\
64 \text { mujeres, con una } \\
\text { edad media de } 68,1 \\
\text { años (DE: } 12,6)\end{array}$ & $\begin{array}{l}\text { Se observaron cambios significativos } \\
\text { ( } p<0,001 \text { ) en fuerza muscular media } \\
\text { (repeticiones): } 9,79 \text { (DE: } 5,11 \text { ) a 9,71 (DE: } \\
\text { 0,42), PA media (mm Hg): } 94,45 \text { (DE: } \\
\text { 13,94) a } 94,28 \text { (DE: } 0,99) \text {, y peso medio } \\
\text { (kg): } 76,11 \text { (DE: } 18,42) \text { a } 75,40 \text { (DE: } 1,38)\end{array}$ & $\begin{array}{l}\text { Fuerza muscular: } \\
\text { Prueba sit-to-stand } \\
\text { 30S (STS30) o prueba } \\
\text { de sentarse y pararse } \\
\text { de } 30 \text { segundos. Peso } \\
\text { y PA: método no } \\
\text { especificado. }\end{array}$ & $\begin{array}{l}\text { No se observaron } \\
\text { efectos adversos } \\
\text { relacionados. }\end{array}$ \\
\hline
\end{tabular}


Tabla 1. Principales características y resultados de los estudios incluidos (continuación)

\begin{tabular}{|c|c|c|c|c|c|c|}
\hline Artículo & Intervención & Tipo de estudio & Población & Hallazgos o resultados & $\begin{array}{c}\text { Métodos de medición } \\
\text { de desenlaces }\end{array}$ & $\begin{array}{c}\text { Riesgos/efectos } \\
\text { adversos } \\
\text { observados }\end{array}$ \\
\hline $\begin{array}{l}\text { Chan, } \\
2016^{(23)}\end{array}$ & $\begin{array}{l}\text { Ejercicio anaeróbico y de resistencia } \\
\text { progresiva intradialítico (máquina } \\
\text { portátil para ejercicios de la parte } \\
\text { superior e inferior del cuerpo durante } \\
\text { la diálisis y para los grupos musculares } \\
\text { más pequeños se usaron pesas de peso } \\
\text { libre o bandas elásticas de resistencia) } \\
3 \text { sesiones/semana, } 30 \text { minutos/sesión } \\
\text { aproximadamente, durante } 12 \text { semanas. } \\
\text { Fue supervisado por un fisiólogo del } \\
\text { ejercicio. }\end{array}$ & $\begin{array}{l}\text { Estudio cuasiex- } \\
\text { perimental de un } \\
\text { solo grupo }\end{array}$ & $\begin{array}{l}22 \text { pacientes en } \\
\text { tratamiento de } H D \text {, } \\
13 \text { hombres y } 9 \\
\text { mujeres, con una } \\
\text { edad media de } 71 \\
\text { años (DE: } 11 \text { ) }\end{array}$ & $\begin{array}{l}\text { Se observó un aumento significativo ( } p \\
<0,001) \text { de la fuerza en extremidades } \\
\text { inferiores del cuerpo (kg): } 62 \text { (DE: } 18,0 \text { ) } \\
\text { a } 77 \text { (DE: } 21,0 \text { ). Sin embargo, no se } \\
\text { observaron cambios significativos en la } \\
\text { fuerza de agarre en la extremidad en la } \\
\text { que se encontraba la fístula (kg): } 20,0 \\
(D E: 6,0) \text { a } 21,0(D E: 6,0) \text {. }\end{array}$ & $\begin{array}{l}\text { Fuerza muscular } \\
\text { en extremidades } \\
\text { superiores: } \\
\text { dinamómetro } \\
\text { hidráulico de } \\
\text { empuñadura (Seahan } \\
\text { SH5001, Heanor, } \\
\text { UK). Fuerza muscular } \\
\text { en extremidades } \\
\text { inferiores: prueba } \\
\text { máxima de } 3 \\
\text { repeticiones utilizando } \\
\text { el dispositivo } \\
\text { de ejercicios } \\
\text { de resistencia y } \\
\text { protocolos de prueba } \\
\text { estándar. }\end{array}$ & $\begin{array}{l}\text { Un caso de } \\
\text { efectos adversos } \\
\text { fue reportado: } \\
\text { el participante } \\
\text { experimentó } \\
\text { mareo en una } \\
\text { ocasión mientras } \\
\text { hacía ejercicio } \\
\text { y, aunque la } \\
\text { PA se mantuvo } \\
\text { normal, la sesión } \\
\text { de ejercicio cesó } \\
\text { inmediatamente. }\end{array}$ \\
\hline $\begin{array}{l}\text { Cigarroa, } \\
2016^{(19)}\end{array}$ & $\begin{array}{l}\text { Ejercicio anaeróbico y de resistencia } \\
\text { muscular ( } 3 \text { fases: calentamiento, } \\
\text { ejercicios y vuelta a la calma) } 2 \text { sesiones/ } \\
\text { semana, } 40 \text { minutos/sesión, durante } \\
8 \text { semanas. Fue supervisado por un } \\
\text { kinesiólogo. }\end{array}$ & $\begin{array}{l}\text { Estudio cuasiex- } \\
\text { perimental de } \\
\text { antes y después } \\
\text { en un solo grupo }\end{array}$ & $\begin{array}{l}13 \text { pacientes en } \\
\text { tratamiento de } \\
\text { HD, } 7 \text { hombres y } 6 \\
\text { mujeres, con una } \\
\text { edad media de } 38,8 \\
\text { años (DE: } 3 \text { ) }\end{array}$ & $\begin{array}{l}\text { Aumento significativo de fuerza } \\
\text { muscular (puntos) en el miembro } \\
\text { inferior derecho: } 223,8 \pm 20,3 \text { a } 232,9 \pm \\
18,8(p=0,02) \text {. Aumento significativo } \\
\text { de fuerza muscular (puntos) en el } \\
\text { miembro inferior izquierdo: } 222,3 \pm 18,9 \\
\text { a } 232,0 \pm 18,0(p=0,00) \text {. Disminución } \\
\text { estadísticamente significativa en } \\
\text { PA diastólica (mm Hg): } 93,9 \pm 3,6 \text { a } \\
88,6 \pm 2,8(p=0,04) \text {. No se observó } \\
\text { disminución significativa en PA sistólica } \\
\text { (mm Hg): } 137,0 \pm 5,4 \text { a } 132,2 \pm 3,6(p= \\
0,18) ; \text { peso }(\mathrm{kg}): 74,4 \pm 5,1 \text { a } 74,3 \pm 5,2(p \\
=0,50), \text { ni IMC }\left(\mathrm{kg} / \mathrm{m}^{2}\right): 25,9 \pm 0,9 \text { a } 25,8 \\
\pm 1,0(p=0,43) .\end{array}$ & $\begin{array}{l}\text { Fuerza muscular: } \\
\text { dinamómetro de } \\
\text { fuerza Load Cell } \\
\text { Microgage, capacidad: } \\
250 \text { lb (OP 2,09996 } \\
\text { mv/v m Art Oficio), } \\
\text { ubicado en la parte } \\
\text { posteroinferior de una } \\
\text { mesa de cuádriceps } \\
\text { y sostenido al brazo } \\
\text { de la máquina } \\
\text { que ejecutaba } \\
\text { el movimiento. } \\
\text { PA: método no } \\
\text { especificado. Peso } \\
\text { y talla: balanza con } \\
\text { tallímetro (Tanita, } \\
\text { WB-3000, Japón) con } \\
\text { sensibilidad de } 0,1 \mathrm{~cm} \\
\text { y } 0,1 \text { kg. }\end{array}$ & $\begin{array}{l}\text { No se observaron } \\
\text { efectos adversos } \\
\text { relacionados. }\end{array}$ \\
\hline
\end{tabular}


Tabla 1. Principales características y resultados de los estudios incluidos (continuación)

\begin{tabular}{|c|c|c|c|c|c|c|}
\hline Artículo & Intervención & Tipo de estudio & Población & Hallazgos o resultados & $\begin{array}{c}\text { Métodos de medición } \\
\text { de desenlaces }\end{array}$ & $\begin{array}{c}\text { Riesgos/efectos } \\
\text { adversos } \\
\text { observados }\end{array}$ \\
\hline $\begin{array}{l}\text { Liao, } \\
2016^{(17)}\end{array}$ & $\begin{array}{l}\text { Ejercicio aeróbico intradialítico (ciclismo: } \\
\text { la intensidad del ejercicio fue de } \\
\text { aproximadamente } 12 \text { a } 15 \text { en la escala de } \\
\text { esfuerzo percibido de Borg) } 3 \text { sesiones/ } \\
\text { semana, } 30 \text { minutos/sesión, durante } 3 \\
\text { meses. Los pacientes se dividieron en } \\
2 \text { grupos de estudio, grupo } \mathrm{E}(\mathrm{n}=20) \text { y } \\
\text { grupo } \mathrm{C}(\mathrm{n}=20 \text { ). El grupo } \mathrm{C} \text { no recibió el } \\
\text { programa de ejercicio. Fue supervisado } \\
\text { por un médico y una enfermera } \\
\text { especializada en rehabilitación. }\end{array}$ & $\begin{array}{l}\text { Estudio experi- } \\
\text { mental aleato- } \\
\text { rizado no cegado }\end{array}$ & $\begin{array}{l}40 \text { pacientes en } \\
\text { tratamiento de } H D \text {, } \\
17 \text { hombres y } 23 \\
\text { mujeres, con una } \\
\text { edad media de } 62 \\
\text { años (DE: } 8 \text { ) }\end{array}$ & 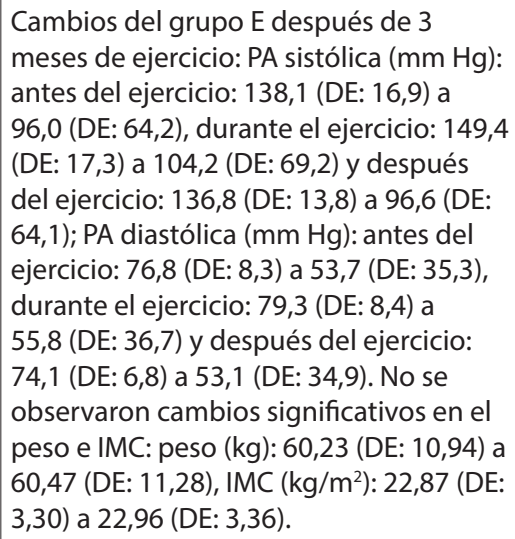 & $\begin{array}{l}\text { PA y peso: método no } \\
\text { especificado }\end{array}$ & $\begin{array}{l}\text { No se observaron } \\
\text { efectos adversos } \\
\text { relacionados. }\end{array}$ \\
\hline $\begin{array}{l}\text { Marinho, } \\
2016^{(14)}\end{array}$ & $\begin{array}{l}\text { Ejercicio anaeróbico intradialítico } \\
\text { (ejercicios de resistencia en ambas } \\
\text { extremidades inferiores, } 60 \% \text { de } \\
\text { intensidad basada en la prueba de } 3 \\
\text { repeticiones máximas [3RM], se utilizaron } \\
\text { bandas elásticas y la intensidad varió } \\
\text { según el color de la banda. Se usaron } \\
\text { tobilleras para realizar } 2 \text { ejercicios } \\
\text { diferentes) } 3 \text { sesiones/semana, en las } \\
\text { primeras } 2 \text { horas de HD, durante } 2 \text { meses } \\
(24 \text { sesiones). Los pacientes se dividieron } \\
\text { en } 2 \text { grupos de estudio: grupo } \mathrm{E}(\mathrm{n}=6) \text { y } \\
\text { grupo } \mathrm{C}(\mathrm{n}=7) \text {. El grupo } \mathrm{C} \text { no recibió el } \\
\text { programa de ejercicio. Fue supervisado } \\
\text { por un educador físico. }\end{array}$ & $\begin{array}{l}\text { Estudio experi- } \\
\text { mental aleato- } \\
\text { rizado no cegado }\end{array}$ & $\begin{array}{l}13 \text { pacientes en } \\
\text { tratamiento de } \\
\text { HD, } 6 \text { hombres y } \\
7 \text { mujeres. Grupo } \\
\text { E: con una edad } \\
\text { promedio de } 71,5 \\
\text { (58,5-87,2) años. } \\
\text { Grupo C: con una } \\
\text { edad promedio } \\
\text { de } 76,0(59,0-83,0) \\
\text { años. }\end{array}$ & $\begin{array}{l}\text { No se encontraron cambios } \\
\text { significativos en el grupo E después de } \\
2 \text { meses de ejercicio: masa magra (\%): } \\
34,7(32,3-53,3) \text { a } 35,7(32,8-50,3), \text { grasa } \\
\text { corporal }(\%): 47,4(33,6-48,8) \text { a } 46,8 \\
(35,0-48,6) \text { e IMC }\left(\mathrm{kg} / \mathrm{m}^{2}\right): 28,5(21,1- \\
35,8) \text { a } 28,4(21,8-36,2) .\end{array}$ & $\begin{array}{l}\text { Composición corporal: } \\
\text { bioimpedancia de } \\
\text { cuerpo completo } \\
\text { multifrecuencia } \\
\text { usando el monitor de } \\
\text { composición corporal } \\
\text { (BCM; Fresenius } \\
\text { Medical Care, Bad } \\
\text { Homburg, Alemania). }\end{array}$ & $\begin{array}{l}\text { No se observaron } \\
\text { efectos adversos } \\
\text { relacionados. }\end{array}$ \\
\hline
\end{tabular}


Tabla 1. Principales características y resultados de los estudios incluidos (continuación)

\begin{tabular}{|c|c|c|c|c|c|c|}
\hline Artículo & Intervención & Tipo de estudio & Población & Hallazgos o resultados & $\begin{array}{c}\text { Métodos de medición } \\
\text { de desenlaces }\end{array}$ & $\begin{array}{c}\text { Riesgos/efectos } \\
\text { adversos } \\
\text { observados }\end{array}$ \\
\hline $\begin{array}{l}\text { Alonso, } \\
2017^{(20)}\end{array}$ & $\begin{array}{l}\text { Ejercicio aeróbico y de resistencia } \\
\text { muscular, intradialítico (utilizando una } \\
\text { pedalera y para resistencia muscular se } \\
\text { realizaron ejercicios contra una resistencia } \\
\text { elástica con ambos miembros inferiores) } \\
3 \text { sesiones/semana, 30-60 minutos/sesión, } \\
\text { durante } 16 \text { semanas. Fue supervisado } \\
\text { por kinesiólogos, médicos, psicólogo, } \\
\text { nutricionista y enfermeros de diálisis. }\end{array}$ & $\begin{array}{l}\text { Estudio cuasiex- } \\
\text { perimental de } \\
\text { antes y después } \\
\text { en un solo } \\
\text { grupo. }\end{array}$ & $\begin{array}{l}29 \text { pacientes en } \\
\text { tratamiento de HD, } \\
14 \text { hombres y } 15 \\
\text { mujeres, con una } \\
\text { edad media de } 50 \\
\text { años (DE: 19) }\end{array}$ & 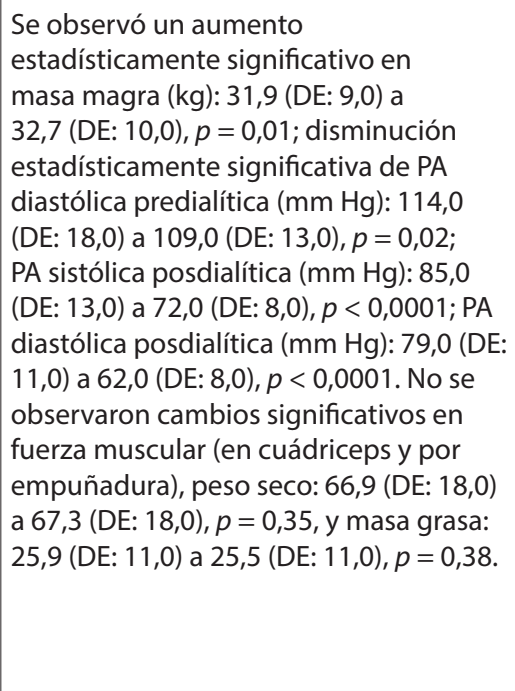 & $\begin{array}{l}\text { Masa magra y masa } \\
\text { grasa: bioimpedancia } \\
\text { utilizando el BCM } \\
\text { (Body Composition } \\
\text { Monitor) de Fresenius. } \\
\text { Fuerza muscular } \\
\text { isométrica de } \\
\text { cuádriceps y del } \\
\text { puño: dinamometría } \\
\text { con los equipos } \\
\text { Nicholas manual tester } \\
\text { y Jamar Hydraulic } \\
\text { Hand Dynamometer, } \\
\text { respectivamente, } \\
\text { además de la prueba } \\
\text { de levantarse de } \\
\text { la silla. Peso seco } \\
\text { y PA: método no } \\
\text { especificado. }\end{array}$ & $\begin{array}{l}\text { Información no } \\
\text { reportada }\end{array}$ \\
\hline $\begin{array}{l}\text { Chang, } \\
2017^{(27)}\end{array}$ & \begin{tabular}{|l} 
Ejercicio aeróbico (taichí de 13 \\
movimientos y un video en el que se les \\
mostraba cómo practicar taichí en casa) 2 \\
sesiones/semana, 1 hora/sesión, durante \\
12 semanas. Los pacientes se dividieron \\
en 2 grupos de estudio, grupo $\mathrm{E}(\mathrm{n}=21)$ \\
y grupo $\mathrm{C}(\mathrm{n}=25)$. El grupo $\mathrm{C}$ no recibió \\
el programa de ejercicio y se le instruyó \\
para que realizara actividades físicas de \\
intensidad ligera, como pasear y hacer \\
ejercicios de estiramiento (el grupo $\mathrm{E}$ \\
también realizó dichas actividades). Fue \\
supervisado por un instructor de taichí \\
certificado.
\end{tabular} & $\begin{array}{l}\text { Estudio cuasiex- } \\
\text { perimental con } \\
\text { grupo control no } \\
\text { equivalente }\end{array}$ & $\begin{array}{l}46 \text { pacientes en } \\
\text { tratamiento de } \\
\text { HD, } 30 \text { hombres y } \\
16 \text { mujeres; grupo } \\
\text { E: con una edad } \\
\text { promedio de } 54,2 \\
\text { años (DE: } 15,2) ; \\
\text { grupo C: con una } \\
\text { edad promedio de } \\
54,6 \text { años (DE: } 12,7 \text { ) }\end{array}$ & $\begin{array}{l}\text { No se observaron cambios significativos } \\
\text { entre el grupo } C \text { y el grupo E en } \\
\text { fuerza muscular }(p=0,01) \text {, pero sí se } \\
\text { registró un aumento significativo de la } \\
\text { resistencia muscular en el grupo } \mathrm{E}(p= \\
0,00) \text {; diferencia }=12,7 \text {. }\end{array}$ & $\begin{array}{l}\text { Fuerza muscular: } \\
\text { prueba sit-to-stand 60S } \\
\text { (STS60) o prueba de } \\
\text { sentarse y pararse de } \\
60 \text { segundos }\end{array}$ & $\begin{array}{l}\text { Información no } \\
\text { reportada }\end{array}$ \\
\hline
\end{tabular}


Tabla 1. Principales características y resultados de los estudios incluidos (continuación)

\begin{tabular}{|c|c|c|c|c|c|c|}
\hline Artículo & Intervención & Tipo de estudio & Población & Hallazgos o resultados & $\begin{array}{c}\text { Métodos de medición } \\
\text { de desenlaces }\end{array}$ & $\begin{array}{c}\text { Riesgos/efectos } \\
\text { adversos } \\
\text { observados }\end{array}$ \\
\hline $\begin{array}{l}\text { Rhee, } \\
2017^{(18)}\end{array}$ & $\begin{array}{l}\text { Ejercicio aeróbico y anaeróbico } \\
\text { intradialítico (aeróbico: ciclismo con } \\
\text { bicicleta ergonómica en posición } \\
\text { supina durante } 30 \text { minutos; anaeróbico: } \\
\text { extensión y flexión del codo, y abducción } \\
\text { lateral del hombro con bandas elásticas, } \\
\text { 2-3 series de } 10-15 \text { repeticiones durante } \\
5-10 \text { min) } 2-3 \text { sesiones/semana, durante } 6 \\
\text { meses. Fue supervisado e individualizado } \\
\text { por dos educadores físicos que eran } \\
\text { estudiantes de doctorado en educación } \\
\text { física. }\end{array}$ & $\begin{array}{l}\text { Estudio cuasiex- } \\
\text { perimental de } \\
\text { medidas repe- } \\
\text { tidas }\end{array}$ & $\begin{array}{l}22 \text { pacientes en } \\
\text { tratamiento de } H D \text {, } \\
9 \text { hombres y } 13 \\
\text { mujeres, con una } \\
\text { edad media de } 57,0 \\
\text { años (DE: } 12,4)\end{array}$ & 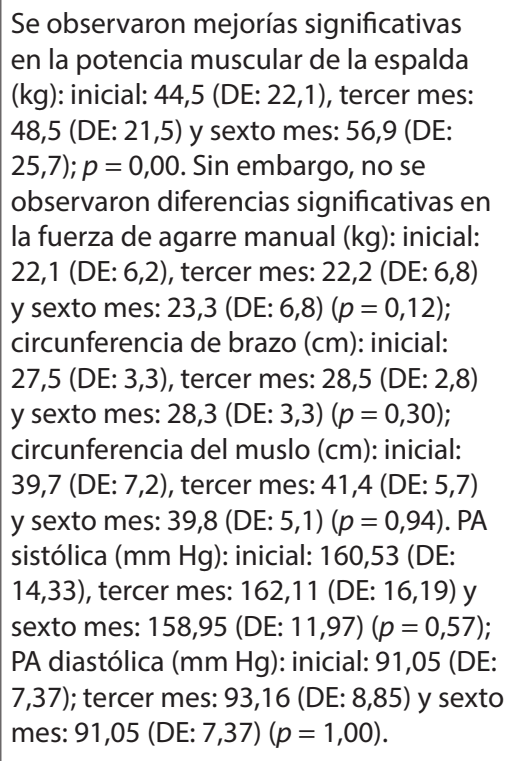 & $\begin{array}{l}\text { Potencia muscular } \\
\text { de la espalda: } \\
\text { dinamómetro digital. } \\
\text { Fuerza de agarre } \\
\text { manual: dinamómetro } \\
\text { mecánico en la mano } \\
\text { sin fístula. Marcadores } \\
\text { antropométricos } \\
\text { y PA: método no } \\
\text { especificado. }\end{array}$ & $\begin{array}{l}\text { Se observaron } \\
\text { efectos } \\
\text { adversos leves } \\
\text { e hipotensión } \\
\text { intradialítica. }\end{array}$ \\
\hline $\begin{array}{l}\text { Chan, } \\
2018^{(11)}\end{array}$ & $\begin{array}{l}\text { Ejercicio anaeróbico y de resistencia } \\
\text { progresiva intradialítico (máquina de } \\
\text { resistencia al peso, bandas elásticas } \\
\text { graduadas por colores y pesas de peso } \\
\text { libre) } 3 \text { sesiones/semana, } 30 \text { minutos/ } \\
\text { sesión aproximadamente, durante } \\
12 \text { semanas. Fue supervisado por un } \\
\text { fisiólogo del ejercicio. }\end{array}$ & $\begin{array}{l}\text { Estudio cuasiex- } \\
\text { perimental de un } \\
\text { solo grupo }\end{array}$ & $\begin{array}{l}22 \text { pacientes en } \\
\text { tratamiento de } H D \text {, } \\
13 \text { hombres y } 9 \\
\text { mujeres, con una } \\
\text { edad media de } 71 \\
\text { años (DE: } 11 \text { ) }\end{array}$ & $\begin{array}{l}\text { No se observaron cambios significativos } \\
(p=0,58) \text { en el peso }(\mathrm{kg}): 72,6 \text { (DE: } 16,3) \\
\text { a } 72,3(\mathrm{DE}: 16,4), \mathrm{IMC}\left(\mathrm{kg} / \mathrm{m}^{2}\right): 28,2(\mathrm{DE}: \\
5,8) \text { a } 28,1(\mathrm{DE}: 5,9) \text { y circunferencia de } \\
\text { cintura }(\mathrm{cm}): 99,6(\mathrm{DE}: 14,5) \text { a 99,1 (DE: } \\
\text { 14,9); diferencia }=0,0 .\end{array}$ & $\begin{array}{l}\text { IMC: obtenido luego } \\
\text { de medir peso y talla. } \\
\text { Circunferencia de } \\
\text { cintura: de acuerdo } \\
\text { con el protocolo } \\
\text { estandarizado del } \\
\text { American College of } \\
\text { Sports Medicine. }\end{array}$ & $\begin{array}{l}\text { No se observaron } \\
\text { serios efectos } \\
\text { adversos } \\
\text { relacionados. }\end{array}$ \\
\hline
\end{tabular}


Tabla 1. Principales características y resultados de los estudios incluidos (continuación)

\begin{tabular}{|c|c|c|c|c|c|c|}
\hline Artículo & Intervención & Tipo de estudio & Población & Hallazgos o resultados & $\begin{array}{c}\text { Métodos de medición } \\
\text { de desenlaces }\end{array}$ & $\begin{array}{c}\text { Riesgos/efectos } \\
\text { adversos } \\
\text { observados }\end{array}$ \\
\hline $\begin{array}{l}\text { da Costa, } \\
2018^{(12)}\end{array}$ & $\begin{array}{l}\text { Ejercicio anaeróbico y de resistencia } \\
\text { progresiva, antes y durante la HD } \\
\text { (ejercicios en la zona de repetición } \\
\text { máxima o sets de ejercicios de simulación } \\
\text { con movilización activa de brazos y } \\
\text { piernas) } 3 \text { sesiones/semana, } 40-50 \\
\text { minutos/sesión, durante } 12 \text { semanas. Los } \\
\text { pacientes se dividieron en } 2 \text { grupos de } \\
\text { estudio: grupo } \mathrm{E}(\mathrm{n}=28 \text { ) y grupo } \mathrm{C}(\mathrm{n}= \\
\text { 24). El grupo C realizó ejercicios de muy } \\
\text { baja intensidad sin carga y progresión. } \\
\text { Fue supervisado por un fisiólogo clínico. }\end{array}$ & $\begin{array}{l}\text { Estudio experi- } \\
\text { mental aleato- } \\
\text { rizado no cegado }\end{array}$ & $\begin{array}{l}52 \text { pacientes en } \\
\text { tratamiento de } H D \text {, } \\
\text { de } 55,7 \text { años (DE: } \\
14,03 \text { ) de edad }\end{array}$ & $\begin{array}{l}\text { Aumento significativo de la fuerza } \\
\text { muscular en miembros inferiores } \\
\text { (repeticiones): } 11,79 \text { (DE: } 3,47) \text { a } 15,18 \\
\text { (DE: } 6,07), p=0,01 \text {; masa magra (kg) } \\
\text { localizada en las piernas del grupo } \\
\text { E: } 14,36 \text { (DE: } 2,95 \text { ) a } 14,78 \text { (DE: } 3,27) ; \\
p=0,04 \text {. No se observaron cambios } \\
\text { significativos en masa magra total (kg): } \\
71,87 \text { (DE: } 13,94 \text { ) a } 72,18 \text { (DE: } 13,54), p \\
=0,27 ; \text { masa grasa total (kg): } 23,81 \text { (DE: } \\
\text { 9,21) a } 23,10 \text { (DE: } 8,40), p=0,61 ; \text { IMC (kg/ } \\
\left.\left.m^{2}\right): 26,36 \text { (DE: } 4,48 \text { ) a } 26,61 \text { (DE: } 4,44\right), p \\
=0,75 ; \text { fuerza de empuñadura (kg): } 65,71 \\
\text { (DE: } 23,27 \text { ) a } 66,61 \text { (DE: } 22,22), p=0,21 \text {. }\end{array}$ & $\begin{array}{l}\text { Masa magra y masa } \\
\text { grasa: absorciometría } \\
\text { de rayos X de energía } \\
\text { dual (DEXA). Fuerza } \\
\text { muscular: Prueba } \\
\text { sit-to-stand } 30 S \\
\text { (STS30) o prueba de } \\
\text { sentarse y pararse de } \\
30 \text { segundos. }\end{array}$ & $\begin{array}{l}\text { Información no } \\
\text { reportada }\end{array}$ \\
\hline $\begin{array}{l}\text { André de } \\
\text { Castro, } \\
2019^{(22)}\end{array}$ & $\begin{array}{l}\text { Ejercicio anaeróbico intradialítico } \\
\text { (ejercicio para fuerza muscular con } \\
\text { ejercicios para dorsales, pectorales, } \\
\text { deltoides, cuádriceps, isquiotibiales, } \\
\text { pantorrilla, tríceps y bíceps) } 3 \text { sesiones/ } \\
\text { semana, } 1 \text { hora y } 50 \text { minutos/sesión, } \\
\text { durante } 39 \text { meses. Fue supervisado por } \\
\text { un educador físico. }\end{array}$ & $\begin{array}{l}\text { Estudio cuasiex- } \\
\text { perimental de } \\
\text { medidas repe- } \\
\text { tidas }\end{array}$ & $\begin{array}{l}43 \text { pacientes en } \\
\text { tratamiento de } H D \text {, } \\
13 \text { hombres y } 30 \\
\text { mujeres, con una } \\
\text { edad media de } 52,8 \\
\text { años (DE: } 13,85 \text { ) }\end{array}$ & $\begin{array}{l}\text { Aumento significativo en la fuerza } \\
\text { muscular (kg): } 27,3 \text { (DE: } 11,58 \text { ) a } 34,8 \\
\text { (DE: } 10,77), p=0,00 \text {. }\end{array}$ & $\begin{array}{l}\text { Fuerza muscular: } \\
\text { método no } \\
\text { especificado }\end{array}$ & $\begin{array}{l}\text { No se observaron } \\
\text { serios efectos } \\
\text { adversos } \\
\text { relacionados. }\end{array}$ \\
\hline
\end{tabular}

* ${ }_{ \pm}$error estándar. rpm: revoluciones por minuto. 
La efectividad de una intervención depende, en gran medida, del grado de adherencia al tratamiento por parte de los pacientes, por lo que se requiere del desarrollo de estrategias que la aumenten, pues la motivación dada por un entorno estimulante resulta favorecedora para que se apeguen al programa de entrenamiento ${ }^{(14)}$. Entonces, es importante conocer la motivación de los pacientes para incrementar sus niveles de ejercicio y la probabilidad de adherirse al programa. Sin embargo, la cantidad de ejercicio estará determinada en gran medida por las características físicas y condiciones de salud de cada paciente, además de su voluntad de participar en el programa.

Una de las principales limitantes de la presente revisión es que el tamaño muestral de los artículos incluidos es diferente, y en su mayoría reducido, con una población promedio de 36,67 pacientes y un total de 660 pacientes en todos los estudios. Cabe mencionar que el estudio con menor tamaño muestral tenía 11 pacientes y el de mayor tamaño tenía 171.

En 13 de los estudios analizados no se reportó la presencia de efectos adversos relacionados con las intervenciones de ejercicio físico que fueron implementadas, ya fuera porque no se presentaron o porque el estudio no lo mencionaba. Sin embargo, en los casos en los que sí se presentaron efectos adversos, estos fueron: $\mathrm{HTA}^{(28)}$, mareos ${ }^{(23)}$ e hipotensión ${ }^{(18)}$, y como riesgos potenciales se manifestaron: fatiga muscular ${ }^{(33)}$, cansancio, náuseas, vómitos, dificultad para respirar, mareos y dolor muscular, articular o coronario ${ }^{(24)}$, lo cual coincide con lo encontrado por Mecca y colaboradores $^{(40)}$ y por Cheema y colaboradores ${ }^{(41)}$.

Aunque es una realidad que estos pacientes son más susceptibles a presentar riesgos y efectos adversos relacionados con la práctica de ejercicio físico con respecto a quienes no padecen la enfermedad ${ }^{(40)}$, en condiciones controladas, estos son bajos ${ }^{(42-44)}$ y, al ser pocos los casos de efectos adversos observados en los estudios analizados (solo uno de cada tipo) y ninguno de ellos considerado como grave, parece ser que se trata de intervenciones seguras. No obstante, esto no exime de la posibilidad de que los riesgos existan, por lo que es deseable que la implementación de un programa de ejercicio se realice bajo la supervisión de un médico, psicólogo, nutriólogo, enfermero o entrenador físico, con la finalidad de evitar riesgos más graves como arritmias, enfermedad coronaria e incluso la muerte súbita asociada ${ }^{(45)}$.

Se consideró un riesgo de sesgo en la presente revisión el hecho de que no todos los artículos incluidos presenta- ron grupo control con fines comparativos; sin embargo, también se incluyeron estudios cuasiexperimentales, que, aunque tienen un menor grado de validez, son de gran utilidad para la evaluación de una intervención.

\section{IMPLICACIONES PARA LA PRÁCTICA CLÍNICA}

De acuerdo con lo observado en los estudios, se recomienda la implementación de programas de ejercicio físico intradialítico que combinen ejercicio anaeróbico y de resistencia para el incremento de la fuerza muscular, el ejercicio anaeróbico para el aumento de masa libre de grasa y el ejercicio aeróbico para la disminución de la PA, con una frecuencia de 2 a 3 veces por semana, una duración entre 30 a 60 minutos por sesión en un período mínimo de 12 semanas y siempre bajo la supervisión de personal bien capacitado.

\section{CONCLUSIONES}

La realización de ejercicio físico parece ser eficiente y segura en cualquier tipo de pacientes, incluyendo adultos mayores, pacientes con un largo tiempo en HD y con otras enfermedades crónicas. Sin embargo, cabe mencionar que es necesario que sea supervisado por personal experto en el área con el fin de evitar riesgos $y$ efectos adversos relacionados. Para el incremento de fuerza muscular, se recomienda la combinación de ejercicio anaeróbico y de resistencia, ya que resulta altamente efectiva; de igual manera, el ejercicio aeróbico y anaeróbico es recomendable para el incremento de la fuerza muscular. Con respecto a los marcadores antropométricos, el ejercicio anaeróbico por sí solo parece ser la opción más recomendable para el aumento de masa libre de grasa. Finalmente, se observó que el ejercicio aeróbico de manera aislada es el más eficaz para la disminución de la PA. Con estos hallazgos se resalta la importancia de continuar las líneas de investigación relacionadas con el tema.

\section{PUNTOS CLAVE}

- La implementación de programas de ejercicio físico aeróbico y de resistencia favorece el aumento de masa muscular de los pacientes con HD.

- Aun en los pacientes ancianos sometidos a HD, el ejercicio físico aeróbico y anaeróbico intradialítico resulta efectivo para aumentar la fuerza muscular de la empunadura del brazo dominante y de las extremidades inferiores. 
- La realización de ejercicio anaeróbico parece ser la opción más recomendable para aumentar masa libre de grasa.

- Una hora de ejercicio físico aeróbico regular durante la HD podría reducir significativamente la PA del paciente hemodializado.

- El grado de adherencia que tengan los pacientes al programa de ejercicios influye de manera importante en la efectividad de la intervención.

\section{Declaración de autoría}

A. P., G. C. y C.O idearon el desarrollo del trabajo y delimitaron las variables de interés. A. P. y G. C. realizaron la búsqueda de la evidencia, la extracción de datos, evaluación de la calidad metodológica de los estudios incluidos y trabajaron en el desarrollo del manuscrito. C. O. y S. C. revisaron el artículo y todas las autoras validaron su versión final.

\section{Fuente de financiación}

El presente artículo no tuvo financiación.

\section{Conflictos de interés}

Las autoras declaran no tener ningún conflicto de interés al redactar el manuscrito.

\section{Referencias bibliográficas}

1. Gorostidi M, Santamaría R, Alcázar R, Fernández-Fresnedo G, Galcerán JM, Goicoechea $\mathrm{M}$, et al. Documento de la Sociedad Española de Nefrología sobre las guías KDIGO para la evaluación y el tratamiento de la enfermedad renal crónica. Nefrología. 2014;34(3):302-316. doi: 10.3265/Nefrologia. pre2014.Feb.12464

2. Fernández MJ, Ibarra JL, Aguas EV, González CE, Quidequeo DG. Beneficios del ejercicio físico en pacientes con enfermedad renal crónica en hemodiálisis. Enferm Nefrol.2018;21(2):167181. doi: $10.4321 /$ s2254-28842018000200008

3. GBD 2017 Disease and Injury Incidence and Prevalence Collaborators. Global, regional, and national incidence, prevalence, and years lived with disability for 354 diseases and injuries for 195 countries and territories, 1990-2017: a systematic analysis for the Global Burden of Disease Study 2017. Lancet. 2018;392(10159):1789-1858. doi: 10.1016/S01406736(18)32279-7

4. Rosa-Diez G, Gonzalez-Bedat M, Ferreiro A, García-García G, Fernandez-Cean J, Douthat W. Burden of end-stage renal disease (ESRD) in Latin America. Clin Nephrol. 2016 Supplement 1;86 (2016)(13):29-33. doi: 10.5414/ CNP86S105
5. Greenwood SA, Naish P, Clark R, O'Connor E, Pursey VA, Macdougall IC, Mercer TH, Koufaki P. Intra-dialytic exercise training: a pragmatic approach. J Ren Care. 2014;40(3):21926. doi: 10.1111 /jorc. 12080

6. Koufaki P, Greenwood SA, Macdougall IC, Mercer TH. Exercise therapy in individuals with chronic kidney disease: a systematic review and synthesis of the research evidence. Annu Rev Nurs Res. 2013;31:235-75. doi: 10.1891/07396686.31 .235

7. Estrategia mundial sobre régimen alimentario, actividad física y salud. [Internet]. Organización Mundial de la Salud [consultado el 30 de junio de 2020.] Disponible en: https://apps. who.int/gb/ebwha/pdf_files/WHA57/A57_R17-sp.pdf

8. Ejercicio aeróbico y anaeróbico, dos formas de adquirir energía. [Internet]. Comisión Nacional de Cultura Física y Deporte; 2017 [consultado el 23 de marzo de 2021]. Disponible en: https://www.gob.mx/conade/prensa/ejercicio-aerobico-y-anaerobico-dos-formas-de-adquirir-energia

9. Rossi AP, Burris DD, Lucas FL, Crocker GA, Wasserman JC. Effects of a renal rehabilitation exercise program in patients with CKD: a randomized, controlled trial. Clin J Am Soc Nephrol. 2014;9(12):2052-8. doi: 10.2215/CJN.11791113

10. Mihaescu A, Avram C, Bob F, Gaita D, Schiller O, Schiller A. Benefits of exercise training during hemodialysis sessions: a prospective cohort study. Nephron Clin Pract. 2013;124(12):72-8. doi: 10.1159/000355856

11. Chan D, Green S, Fiatarone Singh MA, Barnard R, Bonder CS, Cheema BS. Effect of intradialytic resistance training on pulse wave velocity and associated cardiovascular disease biomarkers in end stage renal disease. Nephrology (Carlton). 2018;23(11):1055-1062. doi: 10.1111/nep.13212

12. Rosa CSDC, Nishimoto DY, Souza GDE, Ramirez AP, Carletti CO, Daibem CGL, et al. Effect of continuous progressive resistance training during hemodialysis on body composition, physical function and quality of life in end-stage renal disease patients: a randomized controlled trial. Clin Rehabil. 2018;32(7):899-908. doi: 10.1177/0269215518760696

13. Groussard C, Rouchon-Isnard M, Coutard C, Romain F, Malardé L, Lemoine-Morel S, et al. Beneficial effects of an intradialytic cycling training program in patients with end-stage kidney disease. Appl Physiol Nutr Metab. 2015;40(6):550-6. doi: 10.1139/apnm-2014-0357

14. Marinho SM, Mafra D, Pelletier S, Hage V, Teuma C, Laville $\mathrm{M}$, et al. In Hemodialysis Patients, Intradialytic Resistance Exercise Improves Osteoblast Function: A Pilot Study. J Ren Nutr. 2016;26(5):341-5. doi: 10.1053/j.jrn.2016.03.002

15. Moraes C, Marinho S, Lobo JC, Stockler-Pinto MB, Barros AF, Jacobson LV, et al. Effects of resistance exercise training on acylghrelin and obestatin levels in hemodialysis patients. Ren Fail. 2015;37(5):851-7. doi: 10.3109/0886022X.2015.1033634

16. Bennett PN, Fraser S, Barnard R, Haines T, Ockerby C, Street $\mathrm{M}$, et al. Effects of an intradialytic resistance training programme on physical function: a prospective stepped- 
wedge randomized controlled trial. Nephrol Dial Transplant. 2016;31(8):1302-9. doi: 10.1093/ndt/gfv416

17. Liao MT, Liu WC, Lin FH, Huang CF, Chen SY, Liu CC, et al. Intradialytic aerobic cycling exercise alleviates inflammation and improves endothelial progenitor cell count and bone density in hemodialysis patients. Medicine (Baltimore). 2016;95(27):e4134. doi: 10.1097/MD.0000000000004134

18. Rhee SY, Song JK, Hong SC, Choi JW, Jeon HJ, Shin DH, et al. Intradialytic exercise improves physical function and reduces intradialytic hypotension and depression in hemodialysis patients. Korean J Intern Med. 2019;34(3):588-598. doi: $10.3904 / \mathrm{kjim} .2017 .020$

19. Cigarroa I, Barriga R, Michéas C, Zapata-Lamana R, Soto C, Manukian T. Efectos de un programa de ejercicio de fuerza-resistencia muscular en la capacidad funcional, fuerza y calidad de vida de adultos con enfermedad renal crónica en hemodiálisis. Rev Med Chil. 2016;144(7):844-52. doi: $10.4067 /$ S0034-98872016000700004

20. Alonso R, Midley AD, Crucelegui M, Patiño O, Galarza M, Phillipi R, et al. Evaluación de un programa de actividad física intradialítica en pacientes con hemodiálisis. Nefrol Latinoam. 2017;14(1):4-11. doi: 10.1016/j.nefrol.2016.11.002

21. Anding K, Bär T, Trojniak-Hennig J, Kuchinke S, Krause R, RostJM, et al. A structured exercise programme during haemodialysis for patients with chronic kidney disease: clinical benefit and long-term adherence. BMJ Open. 2015;5(8):e008709. doi: 10.1136/bmjopen-2015-008709

22. Castro APA, Barbosa SR, Mansur HN, Ezequiel DGA, Costa $\mathrm{MB}$, Paula RB. Intradialytic resistance training: an effective and easy-to-execute strategy. J Bras Nefrol. 2018;41(2):215223. doi: 10.1590/2175-8239-jbn-2018-0134

23. Chan D, Green S, Fiatarone Singh M, Barnard R, Cheema BS. Development, feasibility, and efficacy of a customized exercise device to deliver intradialytic resistance training in patients with end stage renal disease: Non-randomized controlled crossover trial. Hemodial Int. 2016;20(4):650-660. doi: 10.1111/hdi.12432

24. DziubekW,Bulińska K, RogowskiŁ, GołębiowskiT, KusztalM, Grochola M, et al. The Effects of Aquatic Exercises on Physical Fitness and Muscle Function in Dialysis Patients. Biomed Res Int. 2015;2015:912980. doi: 10.1155/2015/912980

25. Junqué A, Simó VE, Bernaveu ET, López Ó, Pinedo G, Solé I, et al. Resultado de un programa adaptado de ejercicio físico en pacientes ancianos en hemodiálisis. Enferm Nefrol. 2015;18(1):11-18. doi:

26. Simó VE, Junqué A, Moreno F, Carneiro J, Fulquet M, Pou $\mathrm{M}$, et al. Beneficios del ejercicio físico de baja intensidad durante la sesión de hemodiálisis en el paciente anciano. Nefrología (Madr.). 2015;35(4):347-420. doi: 10.1016/j. nefro.2015.03.006

27. Chang JH, Koo M, Wu SW, Chen CY. Effects of a 12-week program of Tai Chi exercise on the kidney disease quality of life and physical functioning of patients with end-stage renal disease on hemodialysis. Complement Ther Med. 2017;30:7983. doi: $10.1016 /$ j.ctim.2016.12.002

28. Musavian AS, Soleimani A, Masoudi Alavi N, Baseri A, Savari F. Comparing the effects of active and passive intradialytic pedaling exercises on dialysis efficacy, electrolytes, hemoglobin, hematocrit, blood pressure and health-related quality of life. Nurs Midwifery Stud. 2015;4(1):e25922. doi: 10.17795/ nmsjournal25922

29. Maher CG, Sherrington C, Herbert RD, Moseley AM, Elkins M. Reliability of the PEDro scale for rating quality of randomized controlled trials. Phys Ther. 2003;83(8):713-21.

30. Yuste C, Abad S, Vega A, Barraca D, Bucalo L, Pérez-de José A, et al. Valoración del estado nutricional en pacientes en hemodiálisis. Nefrología (Madr.).2013;33(2):243-249. doi: 10.3265/Nefrologia.pre2013.Jan.11670

31. Howden EJ, Leano R, Petchey W, Coombes JS, Isbel NM, Marwick TH. Effects of exercise and lifestyle intervention on cardiovascular function in CKD. Clin J Am Soc Nephrol. 2013;8(9):1494-501. doi: 10.2215/CJN.10141012

32. Hernández A, Mongui K, Rojas Y. Descripción de la composición corporal, fuerza muscular y actividad física en pacientes con insuficiencia renal crónica en hemodiálisis en una unidad renal en Bogotá, Colombia. Rev Andal Med Deporte. 2018;11(2):52-6. doi: 10.1016/j.ramd.2016.09.005

33. Portilla ME, Tornero F, Gil Gregorio P. La fragilidad en el anciano con enfermedad renal crónica. Nefrología. 2016;36(6):609-15. doi: 10.1016/j.nefro.2016.03.020

34. Gracia-Iguacel C, González-Parra E, Barril-Cuadrado G, Sánchez R, Egido J, Ortiz-Arduán A, Carrero J. Definiendo el síndrome de desgaste proteico energético en la enfermedad renal crónica: prevalencia e implicaciones clínicas. Nefrologia (Madr.). 2014;34(4):507-19. doi: 10.3265/Nefrologia. pre2014.Apr.12522

35. Moreno JE, Cruz H. Ejercicio físico y enfermedad renal crónica en hemodiálisis. Rev Nefrol Dial Traspl. 2015;35(4):2129.

36. Johansen KL. Exercise in the end-stage renal disease population. J Am Soc Nephrol. 2007;18(6):1845-54. doi: 10.1681/ ASN.2007010009

37. Fallahi M, Shahidi S, Farajzadegan Z. The Effect of Intradialytic Exercise on Dialysis Efficacy, Serum Phosphate, Hemoglobin and Blood Pressure Control and Comparison between Two Exercise Programs in Hemodialysis Patients. J Isfahan Med School. 2008;26(89):152-61.

38. Song WJ, Sohng KY. Effects of progressive resistance training on body composition, physical fitness and quality of life of patients on hemodialysis. J Korean Acad Nurs. 2012;42(7):947-56. doi: 10.4040/jkan.2012.42.7.947

39. Dungey M, Bishop NC, Young HM, Burton JO, Smith AC. The Impact of Exercising During Haemodialysis on Blood Pressure, Markers of Cardiac Injury and Systemic Inflammation-Preliminary Results of a Pilot Study. Kidney Blood Press Res. 2015;40(6):593-604. doi: 10.1159/000368535 
40. Mecca Giacomazzi C, Jeanty de Seixas R, Prado Lima Figueiredo AE. Los efectos adversos del ejercicio. Nefrologia. 2009;29(4):365. doi: 10.3265/Nefrologia.2009.29.4.5347. en.full

41. Cheema BS, Singh MA. Exercise training in patients receiving maintenance hemodialysis: a systematic review of clinical trials. Am J Nephrol. 2005;25(4):352-64. doi: $10.1159 / 000087184$

42. Sheng K, Zhang P, Chen L, Cheng J, Wu C, Chen J. Intradialytic exercise in hemodialysis patients: a systematic review and meta-analysis. Am J Nephrol. 2014;40(5):478-90. doi: $10.1159 / 000368722$

43. Sakkas GK, Giannaki CD, Karatzaferi C, Maridaki M, Koutedakis Y, Hadjigeorgiou GM, et al. Current trends in the management of uremic restless legs syndrome: a systematic review on aspects related to quality of life, cardiovascular mortality and survival. Sleep Med Rev. 2015;21:39-49. doi: 10.1016/j.smrv.2014.07.006

44. Segura-Ortí E. Ejercicio en pacientes en hemodiálisis: revisión sistemática de la literatura. Nefrología (Madr) 2010;30(2):143-269.

45. Sarmiento OM, Puentes AM, Hernández AE. ¿Cuál es la seguridad de un programa de ejercicio, como intervención, durante la hemodiálisis para el paciente con enfermedad renal crónica? Rev Colomb Nefrol. 2019;6(1):35-47. doi: 10.22265/acnef.6.1.328 